\title{
Sustainability of wave energy resources in southern Caspian Sea
}

\author{
Bahareh Kamranzad $^{\mathrm{a}^{*}}$, Amir Etemad-Shahidi ${ }^{\mathrm{b}}$, Vahid Chegini ${ }^{\mathrm{a}}$ \\ a Ocean Engineering and Technology Research Center, Iranian National Institute for \\ Oceanography and Atmospheric Science, Tehran, Iran, Tel: +98-21-66944873, Fax:$$
+98-21-66944869
$$ \\ *Corresponding author e-mail: kamranzad@inio.ac.ir \\ v_chegini@inio.ac.ir \\ ${ }^{\mathrm{b}}$ Griffith School of Engineering, Gold Coast campus, Griffith University QLD 4222, \\ Australia, Tel: +61-07-5552 9267, Fax: +61-07-5552-8065 \\ E-mail: a.etemadshahidi@griffith.edu.au
}

\begin{abstract}
This study aims to evaluate the wave energy potential and its spatial and temporal variations in the southern Caspian Sea. For this purpose, SWAN model was used to hindcast wave characteristics for 11 years. The wave energy assessment was conducted in four nearshore stations in order to assess the feasibility of wave energy harvesting and locate the most appropriate station. Assessment of seasonal and monthly variations of the mean and maximum wave powers showed that the central station contains the highest values, especially in November; while the north-eastern station has the lowest values with the highest variation of directional distribution of the wave power. Moreover, the seasonal and monthly variability indices indicate a relatively stable wave condition in all stations. The total and exploitable storages of wave energy were also higher in the central station. Therefore, it was concluded that the central station is the most appropriate location for wave energy harvesting. Furthermore, the inter-annual variations of the mean wave power illustrate no significant long-term change in wave power in the southern Caspian Sea. Therefore,
\end{abstract}


considering the relatively stable condition and comparable exploitable storage of wave energy, this area can be a suitable location for developers.

Keywords: wave power; seasonal and monthly distributions; exploitable wave energy; variability index; SWAN

\section{Introduction}

Traditional resources of energy such as oil and gas have undesirable impacts on climate change by increasing the green-house gases emission. This has led to utilizing alternative unlimited resources for supplying energy with low environmental impacts, i.e., renewable energy resources. In areas close to open water bodies, marine phenomena such as winds, waves, tides, etc. can be suitable resources to produce the clean energy. The wave energy with estimated potential of approximately up to 10 TW in the world (Panicker, 1976) has the highest density between the other marine renewable energy resources (Leijon et al., 2003), while having the low environmental impact. Hence, in many countries, researchers have investigated the wave energy potential in coastal areas to help making decisions about the feasibility of supplying the energy demand from the available wave energy.

Since the wave energy is influenced by the atmospheric conditions, other factors such as energy spreading in frequency and direction, and its seasonality should be taken into account in these kinds of studies (Portilla et al., 2013). The assessment of spatial and temporal variations of the wave energy in an area is very important for determining the optimum locations for wave energy harvesting and to adjust the energy provided throughout a year based on the demand. In areas with lower 
variations of available energy, the uncertainty in suggested scenarios for design and selection of the most appropriate wave energy converters decreases.

The recent researches on wave energy assessment also tend to study the spatial and temporal wave energy variations in order to specify the hotspot locations with the lowest seasonality. For example, some studies focused on wave power investigation and its variations in various areas of South and East China Sea from different viewpoints. Zheng and $\mathrm{Li}$ (2015) assessed the inter-annual wave energy variation in China Sea and adjacent waters based on the wave hindcast data and found that the wave power increases $0.20 \mathrm{~kW} / \mathrm{m} /$ year generally, with a maximum value of 0.7 $\mathrm{kW} / \mathrm{m} /$ year in some parts of the domain. Mirzaei et al. (2015) investigated the wave power in the South China Sea based on long-term numerical wave simulation and analyzed the spatial and temporal variations such as seasonality and inter-annual fluctuations. In addition, Wu et al. (2015) assessed the offshore wave energy resources in the East China Sea using wave measurements for three years. They performed the seasonal variability analysis and found that the highest mean wave characteristics exist in winter and autumn, while the extreme values exist in summer and autumn; a point that must be considered for any planning. Zhou et al. (2015) also investigated the temporal-spatial distributions of the wave energy in Beibu Gulf, located at the north west of the South China Sea. They used simulated wave data to determine the hotspot locations with the available wave power considering its monthly, seasonal and annual distributions.

In other areas, as an example, Neill and Hashemi (2013) investigated the wave power temporal and spatial variability in the northwest European shelf seas using a 7-yearly simulated wave data and showed that the uncertainty is greater during October to March. Neill et al., (2014) also assessed the inter-annual and seasonal variability of 
wave energy around Orkney, north of Scotland during a ten-year period and showed that the variability of the wave energy is considerable.

Hiles et al. (2014) used the 9-year wave data to estimate the wave energy near Hot Springs Cove, Canada and investigated the temporal variation of the wave power in a selected site to assess the feasibility of wave energy extraction. In Gulf of Mexico and Caribbean Sea, Appendini et al. (2015) evaluated the wave energy potential and its temporal and spatial variations and indicated that according to the monthly variability, the southern part presents lower variability.

Rute Bento et al. (2015) assessed the wave energy potential in Galway Bay and indicated that the spatial and temporal distributions of the wave power illustrate a difference in wave energy values between winter and summer. Furthermore, López et al. (2015) assessed the offshore and nearshore wave energy in Peru and found that the large amount of wave power and low seasonal variation, make it suitable for use. Wave energy resources around Australia were also reviewed by Morim et al (2014), and they found that in most of the southern Australian states, the coastal and nearshore wave energy resources are fairly sustained throughout the year, and the highest mean wave power exists in spring and winter. In addition, Reguero et al. (2015) used 60 years of wave dataset to determine the global mean wave power and its monthly and seasonal variability as well as decadal long-term changes. Kamranzad et al. (2015) also evaluated the climate change impact on wave energy in the Persian Gulf by comparing the future and current wave energies which have been estimated and evaluated by Etemad-Shahidi et al. (2011) and Kamranzad et al. (2013). There are few studies focused on investigating the wave energy resources in enclosed water bodies (Appendini et al. 2015; Ortega et al. 2013). These areas may contain lower energy; however, they may be feasible areas for wave energy extractions due to 
the practical advantages for implementation, operation and maintenance of wave energy converters (Appendini et al., 2015). As discussed by Portilla et al. (2013), in addition to the conventional areas including storm belts, other areas with lower energy level, but greater potential efficiency due to the temporally stable conditions needs to be studied as well.

Caspian Sea is the largest enclosed water body in the world and is threatened by environmental impacts due to the rapid growth of industries around it. The southern Caspian Sea experiences high waves due to its long fetch that makes its coasts potential locations for wave energy extraction. Kamranzad et al., (2012) assessed the annual average wave power in southern Caspian Sea and showed that the highest powers can be found in middle parts. Hadadpour et al. (2014a, b, c) determined the wave energy and hot spots in Anzali port located in the western part of the southern Caspian Sea in a local scale based on a one-year simulated data, which is not sufficient for assessment of the temporal variations. Rusu and Onea (2013) also estimated the wind and wave energy in offshore locations in the Caspian Sea far from the southern coastlines and stated that comparing to the wind, the wave energy is not sufficient. However, a recent research has shown that a nearshore study area with higher available wave power is preferred, and nearshore hotspots can be determined as possible locations for wave energy farming (Monteforte et al., 2015). In addition, the temporally stable conditions in areas with lower energy may result in greater efficiency (Portilla et al., 2013).

The previous researches provided general information based on only mean or maximum wave power values and give no information about the sustainability and variability of the wave energy resources in the Caspian Sea and especially in the southern parts, which are potential locations for wave energy extraction. In addition, 
the previous studies did not investigate the inter-annual variations of the wave energy which is critical for wave energy assessment (Neill and Hashemi, 2013).

This study provides a new contribution to the available wave energy status in southern Caspian Sea. First, this study will represent a new wave energy assessment based on an 11-yearly numerical wave modeling and evaluates the spatial distribution of the wave power in the whole domain. Second, the temporal variations will be assessed in monthly, seasonal and annual scales. Third, the nearshore wave energy resources and its monthly, seasonal and inter-annual variation will be discussed as well as the available and exploitable wave energy values in different stations. The study provides useful information for developers and scientists about the feasibility and sustainability of wave energy absorption in the largest enclosed sea of the world.

\section{Materials and methods}

\subsection{Study area and data resources}

Caspian Sea is the largest enclosed water body with a surface area of $371000 \mathrm{~km}^{2}$ and volume of $78200 \mathrm{~km}^{3}$. It is located between Asia and Europe and is bordered by Russia (northwest), Azerbaijan (west), Iran (south), Turkmenistan (southeast) and Kazakhstan (northeast) (Fig. 1). There is only one access through Russia's Volga River to the Black Sea and Baltic Sea. The depth in Caspian Sea increases moving towards the south and reaches the deepest areas (approximately $1 \mathrm{~km}$ ) in southern Caspian Sea, which contains $66 \%$ of the total water volume (Amirahmadi, 2000). The southern Caspian Sea bathymetry including the depth contours up to $38.5^{\circ} \mathrm{N}$ is shown in Fig. 2. 


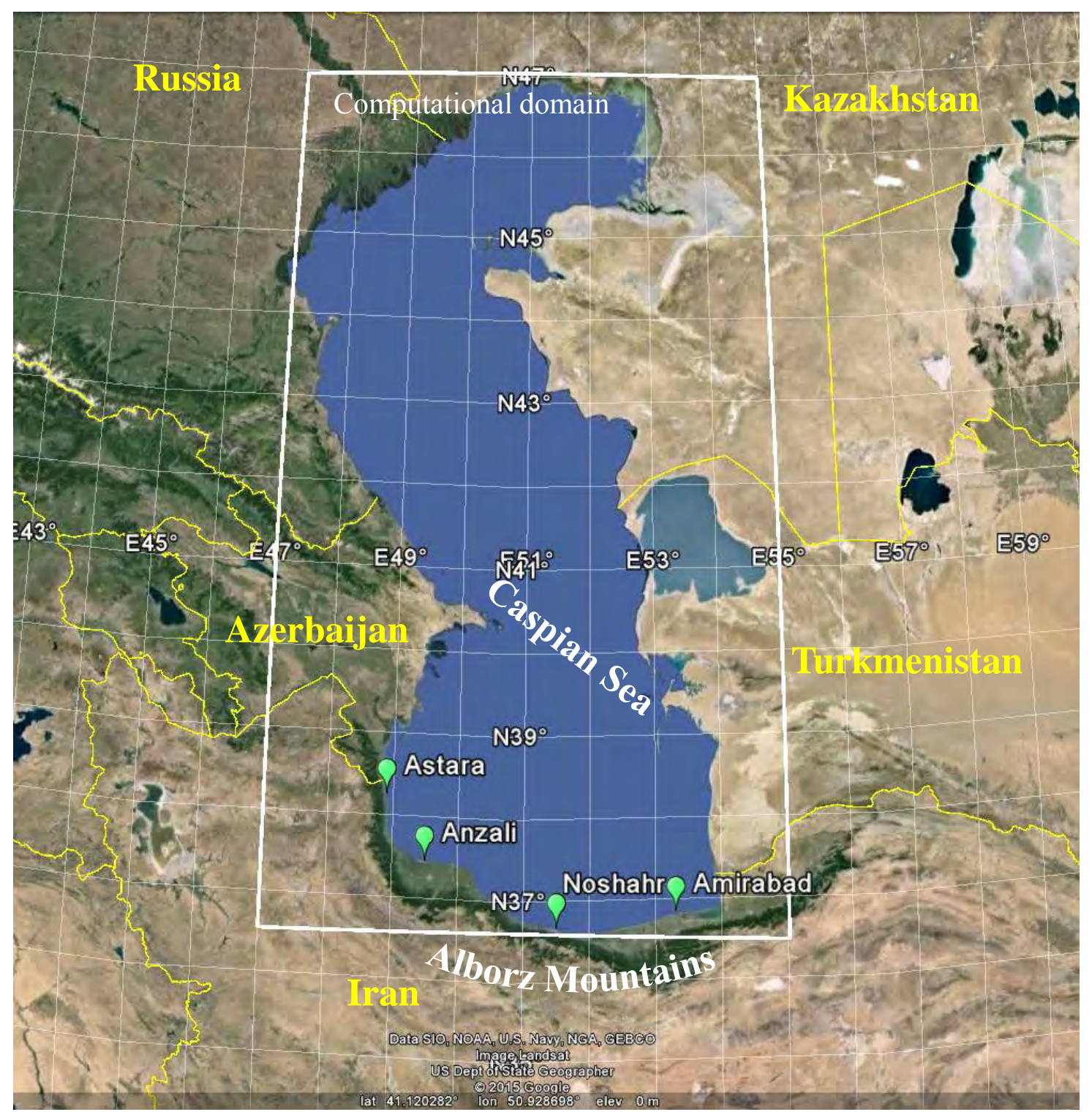

Fig. 1. Location of the Caspian Sea, computational domain and nearshore stations 


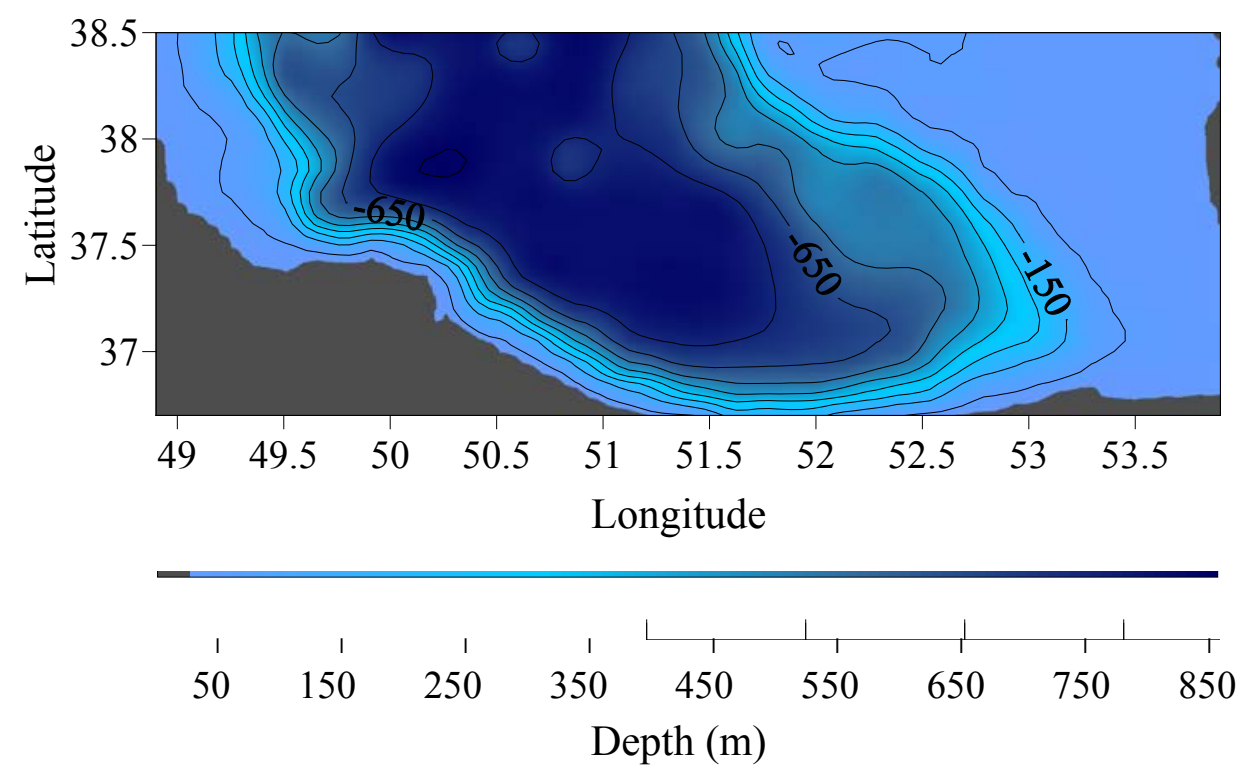

Fig. 2. Location, bathymetry and depth contours of the southern Caspian Sea

The Iranian coastlines of the Caspian Sea located at the southern parts, is about 820 $\mathrm{km}$ being in the vicinity of Alborz Mountains. This area forms a hinterland with a relatively compact vegetation and mild weather and consequently, an attractive and beautiful region for farming, settlement and tourism. Hence, to supply the energy demand for this highly populated region, the wave energy in southern Caspian Sea can be utilized.

Due to the lack of long-term high coverage wave measurements, the wave characteristics were obtained from the numerical hindcasting for an 11-yearly period using SWAN model (Booij et al., 1999). This model has been previously used for wave simulation in the Caspian Sea (Hadadpour et al., 2014b) and provided an acceptable accuracy with the wave climate in this area. In this study, SWAN was forced with the available ECMWF (European Centre for Medium-Range Weather Forecasts) wind data for an 11-yearly period (1992 to 2002) consisting of spatial and temporal resolutions of $0.5^{\circ}$ and 6 hours, respectively. This modified ECMWF product (including both operational and reanalysis versions with the additional 
modifications using local data in Seas surrounding Iran) was previously validated comparing to the local wind measurements (Chegini et al., 2006). Bathymetry information of ETOPO2 dataset obtained from NOAA's National Geophysical Data Center (NGDC), with a spatial resolution of $1 \mathrm{~min}$ (about $1.67 \mathrm{~km}$ ) were used as model input. Wave measurements near Amirabad and Anzali ports (Fig. 1) were also used for calibration and verification of the model, respectively.

SWAN was performed in two-dimensional non-stationary mode with the computational time step of $10 \mathrm{~min}$ in the computational domain (Fig. 1), and the output grid resolution was $0.2^{\circ}$ with a time step of $3 \mathrm{hrs}$. , in the southern Caspian Sea. Komen's formulation was used for exponential growths of wind input (Moeini et al. 2012).

Model calibration was carried out in order to tune the model parameters so that the outputs show the most possible accordance with the measured data. The verification of the model was conducted to check the reliability of the model in another location and/or another period of time. Table 1 shows the results of the model verification in the Anzali station using error indices of Bias, correlation coefficient $(C C)$, root mean square error (RMSE) and scatter index $(S I)$ which are calculated using the following equations:

$$
\begin{aligned}
& \text { Bias }=\bar{y}-\bar{x} \\
& C C=\frac{\sum_{i}\left(\left(x_{i}-\bar{x}\right) \times\left(y_{i}-\bar{y}\right)\right)}{\sqrt{\sum_{i}\left(x_{i}-\bar{x}\right)^{2} \sum_{i}\left(y_{i}-\bar{y}\right)^{2}}} \\
& R M S E=\sqrt{\frac{\sum_{i}\left(x_{i}-y_{i}\right)^{2}}{n}} \\
& S I=\frac{R M S E}{\bar{x}}
\end{aligned}
$$


in which, $x_{\mathrm{i}}$ and $y_{i}$ represent the measured and modeled values, while $\bar{x}$ and $\bar{y}$ are their average values, respectively.

According to Table 1, the modeling results are satisfactory comparing to the measured values in verification. In order to model all ranges of wave parameters' values with the least scattering, SI was considered as the most important error index. Therefore, the model was calibrated so that the SI is minimized in both calibration and verification periods.

Table 1. Error indices for wave model verification in buoy location

\begin{tabular}{ccc}
\hline Error index & Significant wave height & Peak period \\
\hline Bias & $-0.02 \mathrm{~m}$ & $-0.20 \mathrm{~s}$ \\
$C C$ & 0.96 & 0.85 \\
$R M S E$ & $0.12 \mathrm{~m}$ & $0.86 \mathrm{~s}$ \\
$S I(\%)$ & 30.8 & 23.2 \\
\hline
\end{tabular}

After verifying the model, it was performed for 11 years according to the available wind field and the time series of significant wave height and wave period were used to estimate the wave power (Abbaspour and Rahimi, 2011; Henfridsson et al., 2007). The wave energy density is calculated from Eq. (5) (Hughes and Heap, 2010). $E=\frac{1}{16} \rho g H_{s}^{2}$

where $\rho, g$ and $H_{s}$ denotes the water density, gravitational acceleration and significant wave height, respectively. The wave energy flux (wave power) is specified as: $P=E C_{g}=E C n$ in which $C$ is the wave speed and $n$ shows the ratio of wave group speed to the wave speed and is approximately equal to 0.5 in deep water. $C$ is calculated by the wave 
length divided by the wave period ( $T$ ) while the wave length is equal to $g T^{2} / 2 \pi$ in deep water. Hence, the wave power can be estimated as follows.

$$
P=\frac{1}{16} \rho g H_{S}^{2} \times \frac{g T}{2 \pi} \times 0.5 \approx 0.49 H_{S}^{2} T
$$

Since the real sea state includes a large number of regular waves, a variance spectral density function is used to describe a mixture of different amplitudes, frequencies and directions. The wave power per unit width of waves in deep water is obtained by (Abbaspour and Rahimi, 2011):

$$
P=\approx 0.49 H_{S}^{2} T_{e}
$$

in which $T_{e}$ is the energy period and is equal to $T_{p}$ multiplied by a factor which is 0.9 for a standard JONSWAP spectrum with a peak enhancement factor of $\gamma=0.33$ (Abbaspour and Rahimi, 2011).

\section{Results}

\subsection{Spatial and temporal distributions of the wave power}

Using Eq. (8), the wave power was calculated for each grid point of the model covering the southern Caspian Sea, using the time series of the wave characteristics. Fig. 3 shows the spatial distribution of the mean wave power in the southern Caspian Sea. According to this figure, the wave energy is the highest in the central parts of the southern Caspian Sea. In nearshore areas, the wave power is also the highest in central parts, and it is higher in western parts comparing to that of the eastern parts. This is in line with the results of Hadadpour et al. (2014b) which estimated the wave power potential in Anzali, located at the west of the southern Caspian Sea, based on the time series of wave characteristics for one year. They showed that the highest wave powers 
exist in the eastern parts of the domain, i.e., towards the central parts of the southern Caspian Sea.

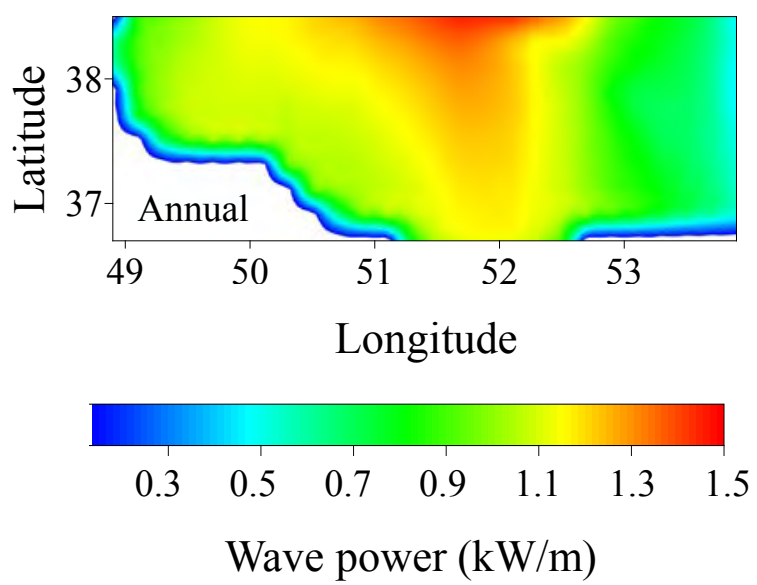

Fig. 3. Annual wave power distribution in southern Caspian Sea

Estimating the mean wave energy is not enough for making 1 decision and the temporal and directional variations should be taken into account in order to assign the harvesting potential by a specific system (Portilla et al., 2013). Therefore, the seasonal and monthly distributions of the mean wave power in the southern Caspian were also analyzed (Figs. 4 and 5). Fig. 4 indicates that the highest wave power exists in autumn with the highest value of $2.2 \mathrm{~kW} / \mathrm{m}$ in the domain. Afterwards, it reduces in winter and reaches the lowest values in spring (approximately $0.95 \mathrm{~kW} / \mathrm{m}$ ). Subsequently, the wave power increases in summer to reach the highest values in autumn. In all seasons, the highest and lowest wave powers in the domain exist in the central and eastern parts of the southern Caspian Sea, respectively; while in autumn, the difference between the wave power values in western and eastern parts increases. 

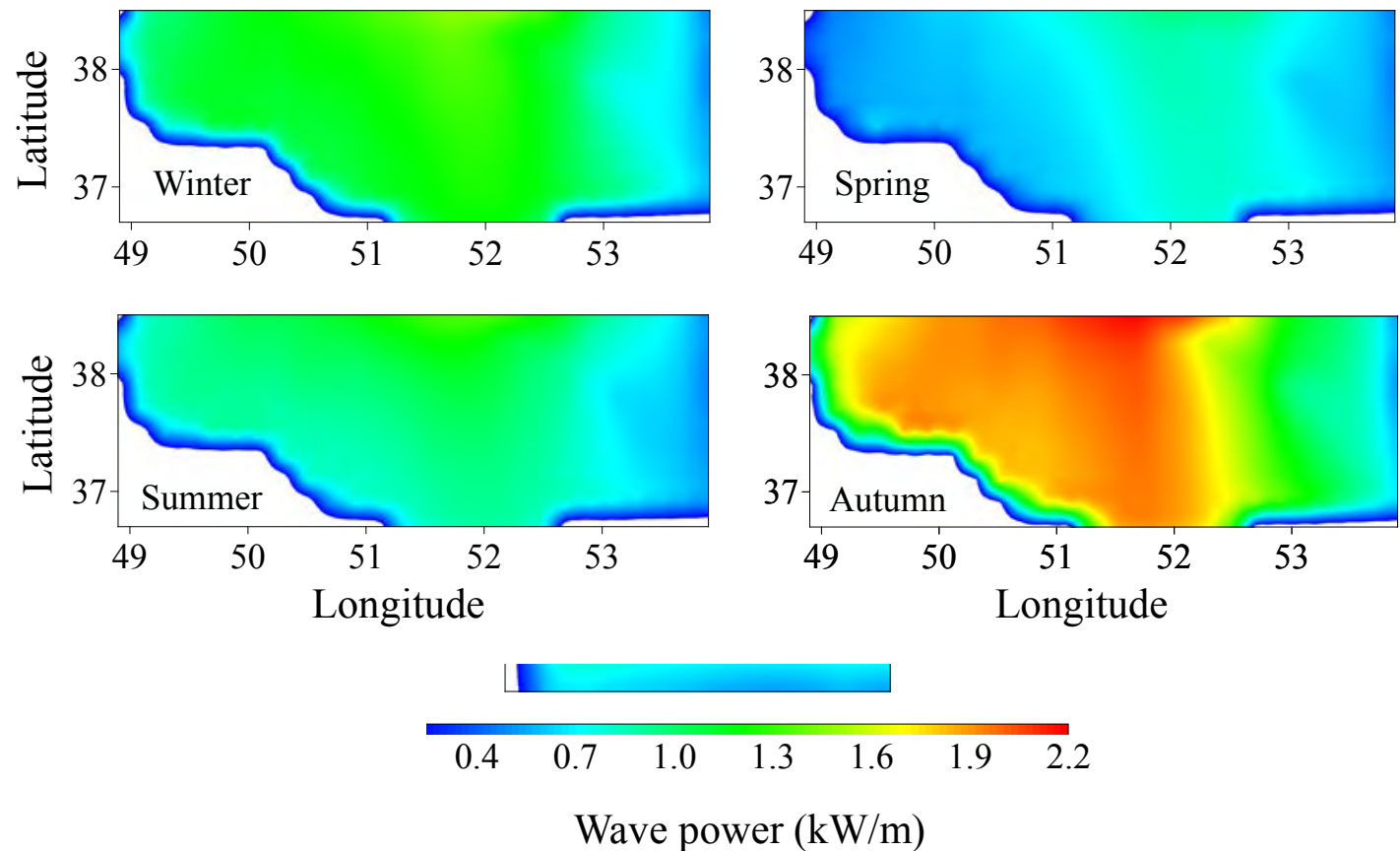

Fig. 4. Seasonal mean wave power distribution in southern Caspian Sea

Monthly variation of the wave power distribution in southern Caspian Sea (Fig. 5)

illustrates that the highest wave power values can be found during September to November reaching the maximum value of $2.4 \mathrm{~kW} / \mathrm{m}$ in November. The lowest values are observed during April to August with an increase in June that leads the average wave power increases in summer (compared to that of spring). In addition, almost in all months, the mean wave power is higher in the central areas of the southern Caspian Sea while in October and November; the hotspots exist in the western parts, as well. 

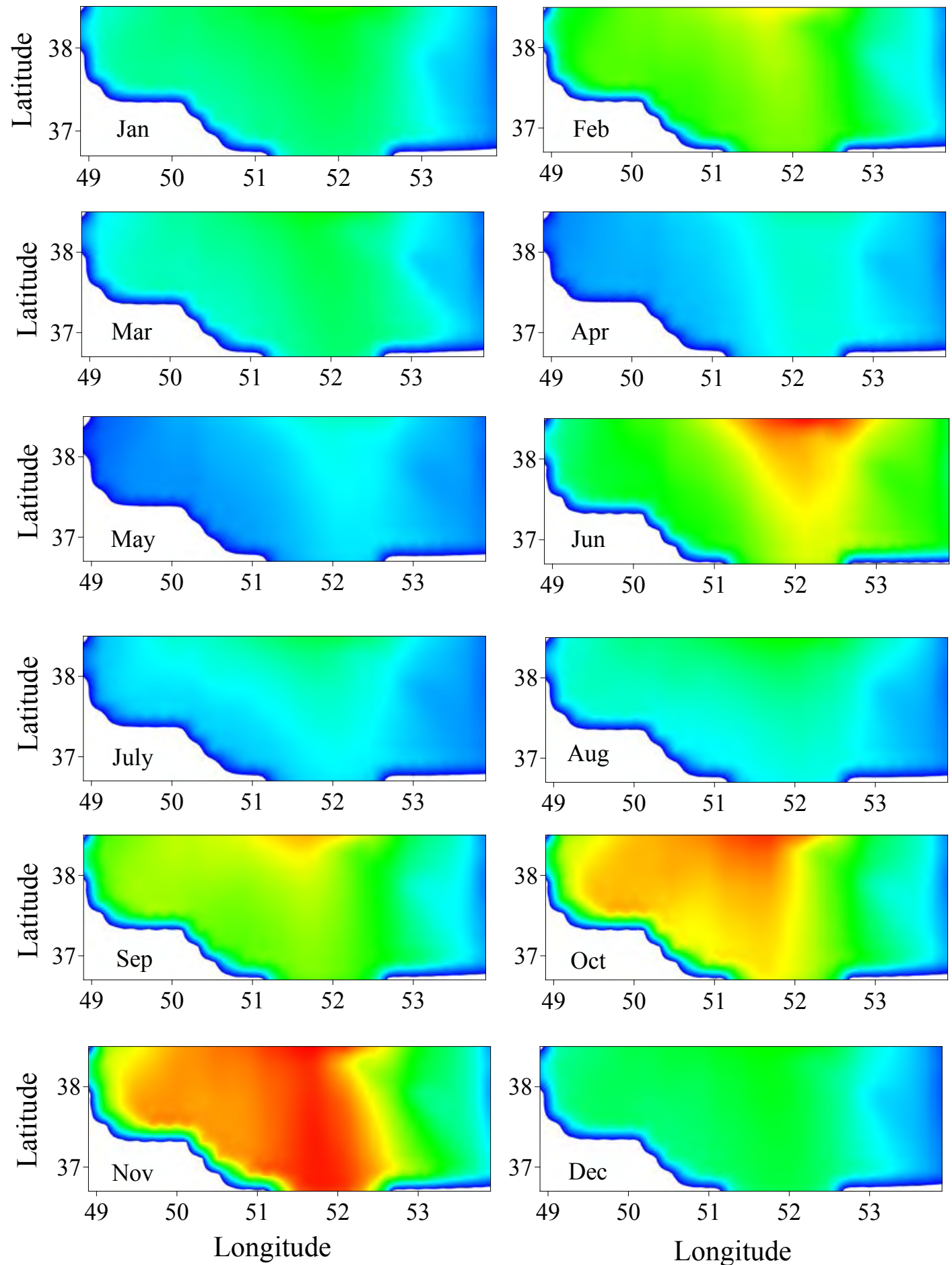

$$
\begin{array}{llllllll}
0.3 & 0.6 & 0.9 & 1.2 & 1.5 & 1.8 & 2.1 & 2.4 \\
\multicolumn{6}{c}{\text { Wave power }(\mathrm{kW} / \mathrm{m})}
\end{array}
$$

Fig. 5. Monthly mean wave power distribution in southern Caspian Sea 


\subsection{Wave power distribution in nearshore stations}

According to Figs. 3 to 5, the central stations seem to be the most appropriate areas for wave energy harvesting due to their highest mean wave power. However, the maximum values, seasonal and directional variations should also be assessed. Hence, the wave power was evaluated in selected nearshore stations (Fig. 1). These stations were selected based on the importance of the region, and they cover the most important cities of the northern coasts of Iran named Astara, Anzali, Noshahr and Amirabad, located in the northwestern, western, central and eastern parts of the nearshore areas of the southern Caspian Sea, respectively. Table 2 shows the location of the selected stations.

Table 2. Location of selected nearshore stations

\begin{tabular}{cccc}
\hline Station ID & $\begin{array}{c}\text { Station } \\
\text { no. }\end{array}$ & Long. (deg) & Lat. (deg) \\
\hline Astara & 1 & 48.90 & 38.30 \\
Anzali & 2 & 49.50 & 37.50 \\
Noshahr & 3 & 51.50 & 36.70 \\
Amirabad & 4 & 53.30 & 36.90 \\
\hline
\end{tabular}

\subsubsection{Seasonal and monthly variations of the wave power in the nearshore}

\section{stations}

Time series of the wave power were obtained for each of the four nearshore stations, and the seasonal variations of the mean and maximum wave power were determined (Fig. 6). Fig. 6 illustrates that in all stations, the highest mean wave power exists in autumn while the lowest value exists in spring. In addition, the mean wave power in Noshahr station is about $1.8 \mathrm{~kW} / \mathrm{m}$ and higher than those of other stations, while the mean wave power in Astara in the lowest. 
Although the extreme sea states are not an important measure for annual available wave energy because of their low occurrence, they may bring risks to the wave energy converters and should be considered in design (Wu et al., 2015). Therefore, the maximum seasonal values were also assessed. Fig. 6 indicates that the maximum wave power is also higher at Noshahr station except in spring, when the maximum wave power in Amirabad is slightly higher. The highest maximum wave power in Astara, Anzali and Noshahr are approximately 13.8, 42.9 and $98 \mathrm{~kW} / \mathrm{m}$, respectively in autumn and the highest maximum wave power in Amirabad is approximately 35 $\mathrm{kW} / \mathrm{m}$ in spring.
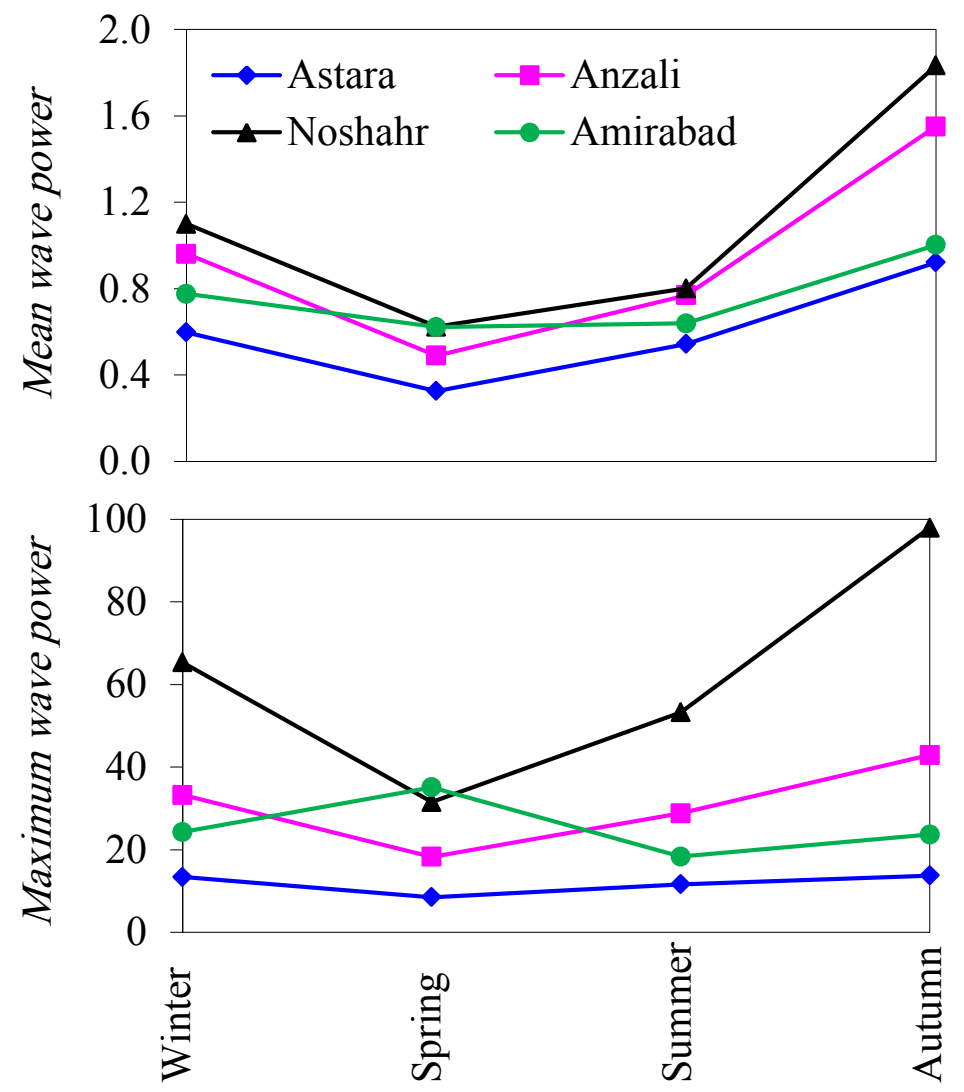

Fig. 6. Seasonal wave power $(\mathrm{kW} / \mathrm{m})$ in different stations 
Monthly variations of the statistical indices of the wave power, including mean, maximum, $10 \%$ and $90 \%$ probability of exceedance (which indicate the extreme and lowest wave power conditions, respectively), are shown in Fig. 7. According to this figure, Noshahr has the highest wave power among the other stations, in terms of all statistical indices except for some months, e.g. April to June, for the mean wave power. The highest mean, maximum and $10 \%$ exceedance of the wave power occur from September to November and reach the highest values in November. The differences between the available mean, maximum and $10 \%$ exceedance of the wave power in different stations increase also during this period, when the highest values can be found in Noshahr. Moreover, the wave power is the lowest during March to August almost in all stations, and the available mean and extreme wave power is the lowest in Astara. Based on these statistical indices, the available wave power is higher in Noshahr, Anzali and Amirabad, respectively while the wave power in Astara is the lowest. However, the mean and maximum wave power in Amirabad exceeds those of the other stations during April to June and March to April, respectively. 

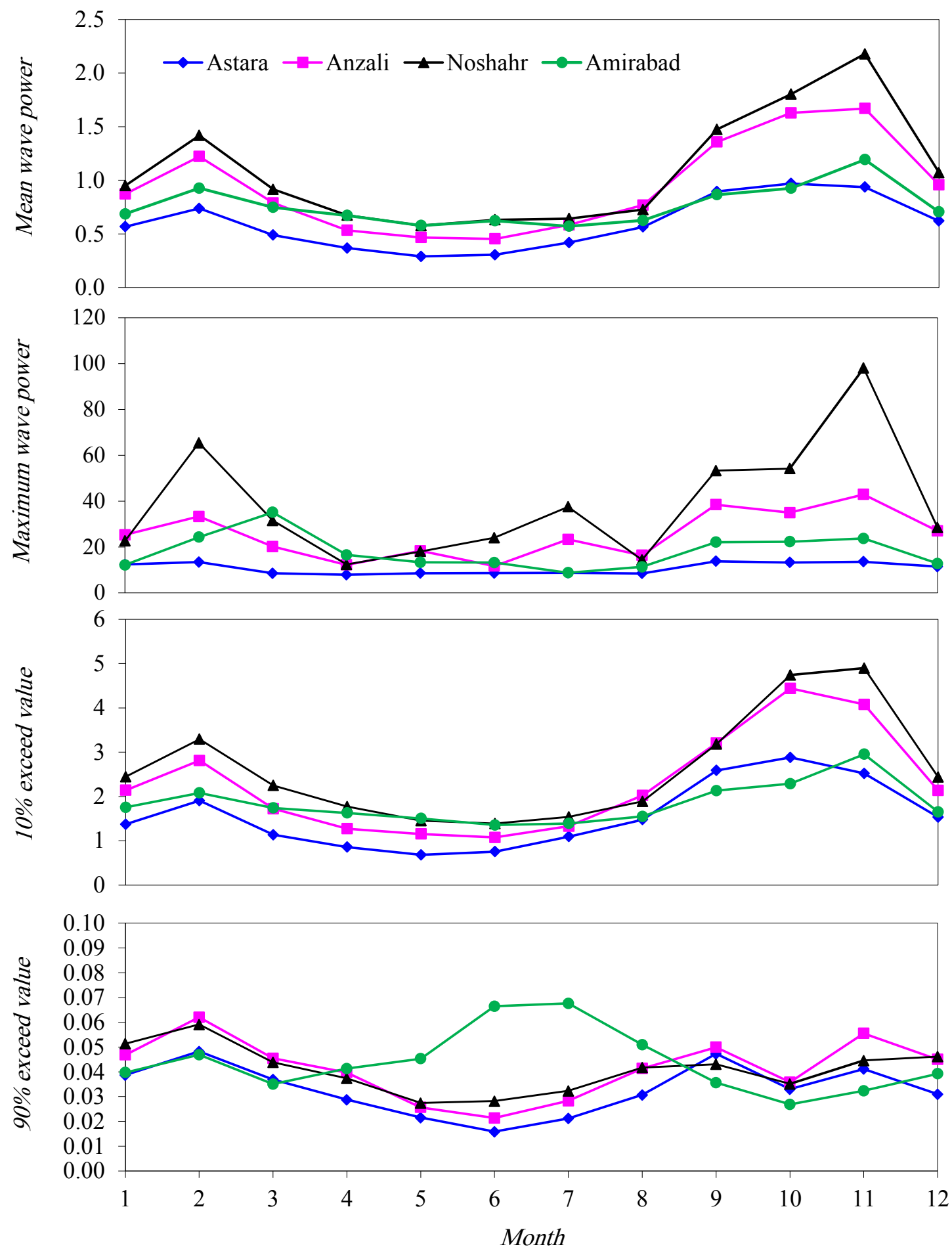

Fig. 7. Monthly wave power $(\mathrm{kW} / \mathrm{m})$ in different stations

In order to evaluate the stability of the seasonal and monthly wave powers and to determine the temporal variability of wave power, Seasonal and Monthly Variability Indices (SVI and MVI, respectively) were used (Cornett, 2008; Zheng et al., 2013). 
The SVI/MVI is the ratio of the difference between the maximum and minimum seasonal/monthly mean wave power and the annual mean wave power (Sanil Kumar and Anoop, 2015) and the lowest values imply the lowest seasonality and more stable conditions. The SVI and MVI values for all stations are shown in Table 3, which represents that the SVI value ranges between 0.51 at Amirabad and 1.15 in Anzali while the MVI value ranges between 0.82 in Amirabad and 1.50 in Noshahr. This means that the wave power variation is lower in Amirabad, which shows the lowest seasonal and monthly variations. However, the amount of SVI and MVI in other stations are not too high compared to the other cases. For example, Sanil Kumar and Anoop (2015) estimated the MVI varies from 1.5 to 3 in the Indian shelf seas and Zhou et al. (2015) represented that the maximum MVI is about 1.1 in Beibu Gulf, China that implies a stable wave condition in monthly variation. Therefore, it can be concluded that the wave energy condition is, to some extent, stable in all stations. In addition, Astara is not an appropriate area for wave energy harvesting due to its low mean and maximum wave powers.

Table 3. Monthly and seasonal variability indices

\begin{tabular}{ccccc}
\hline Station: & Astara & Anzali & Noshahr & Amirabad \\
\hline SVI & 1.01 & 1.15 & 1.13 & 0.51 \\
MVI & 1.16 & 1.31 & 1.50 & 0.82 \\
\hline
\end{tabular}

\subsubsection{Directional distribution of the wave power}

In addition to the temporal variation, the directional distribution of the available wave power and its variation during different seasons are also important for design of wave energy converters. Reguero et al. (2015) considered the directional distribution of the wave energy and indicated that the global estimated offshore wave power will be 
reduced by half when considering the direction of the energy. Figs. 8 to 11 depict the variation of the wave power roses during different seasons. Fig. 8 shows that the prevailing wave propagation is from North East (NE) during all seasons in Astara and the frequency of highest wave powers in NE direction increases in autumn. Fig. 9 illustrates that the prevailing wave direction is from Northern-NE (N-NE) in Anzali. However, the prevailing direction is NE during autumn. In addition, the high wave power frequencies increase also in autumn.

In Noshahr (Fig. 10), the prevailing wave propagation direction is from the North $(\mathrm{N})$, and it is the same in spring and summer. In autumn, the dominant direction rotates from NE to N-NE in winter. In addition, the extreme wave power frequencies are the highest in autumn. According to Fig. 11, the annual and spring dominant wave directions are from Northern-North West (N-NW) in Amirabad. In summer, it changes to NW while is autumn, the NE waves are prevailing. In winter, propagation directions ranging from NE to N-NW are dominant. To sum up, the directional distributions of the waves are relatively stable in Astara while the variation of the wave propagation direction in Amirabad is considerably more than those of other stations. The annual wave direction changes from NE in Astara into N-NE, N and NNW in Anzali, Noshahr and Amirabad, respectively and the dominant wave direction is from NE during autumn in all stations. 

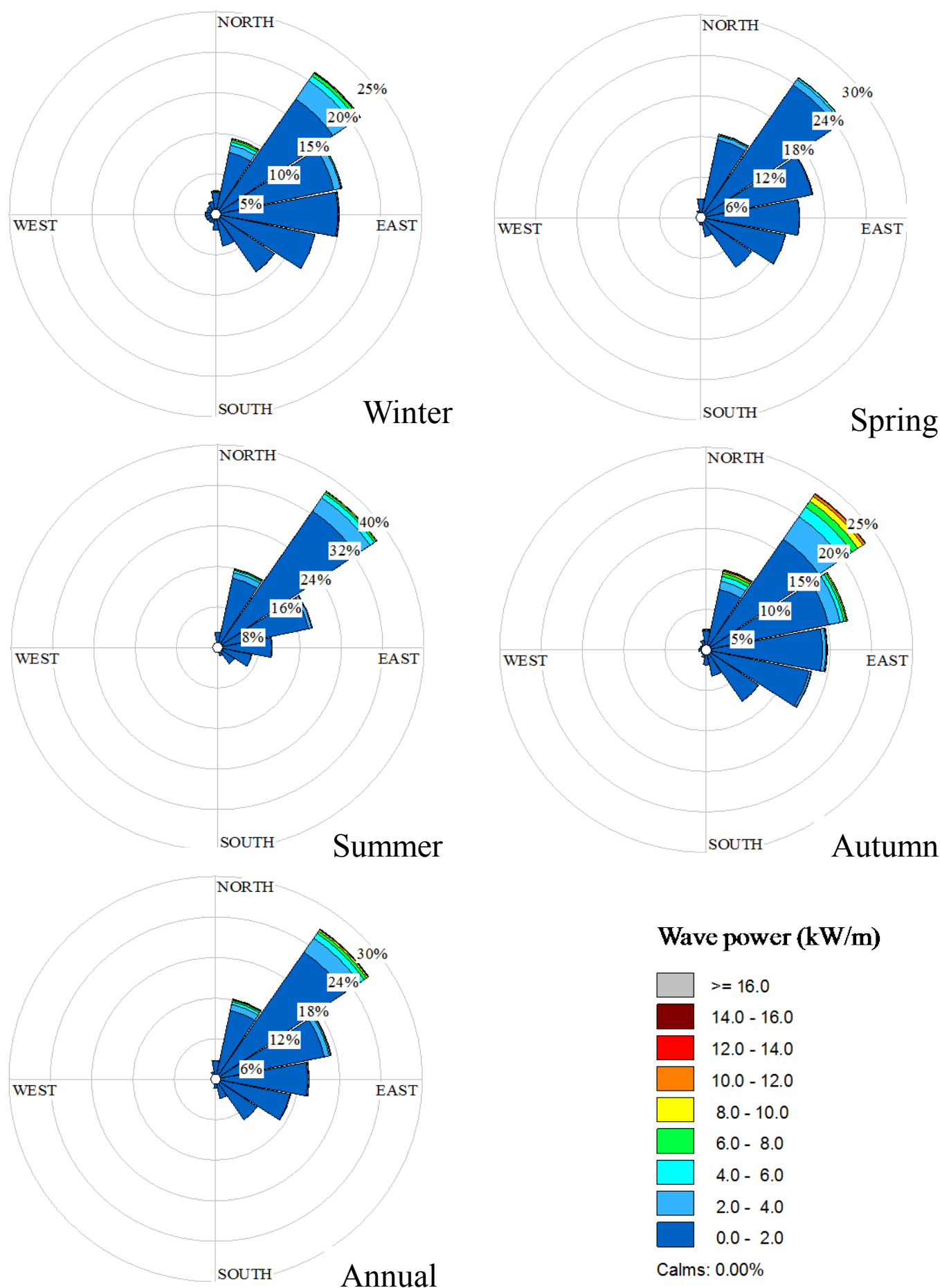

\section{Wave power $(\mathrm{kW} / \mathrm{m})$}

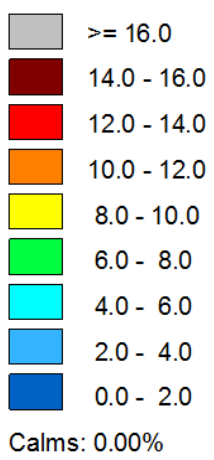

Fig. 8. Seasonal and annual wave power roses in Astara 

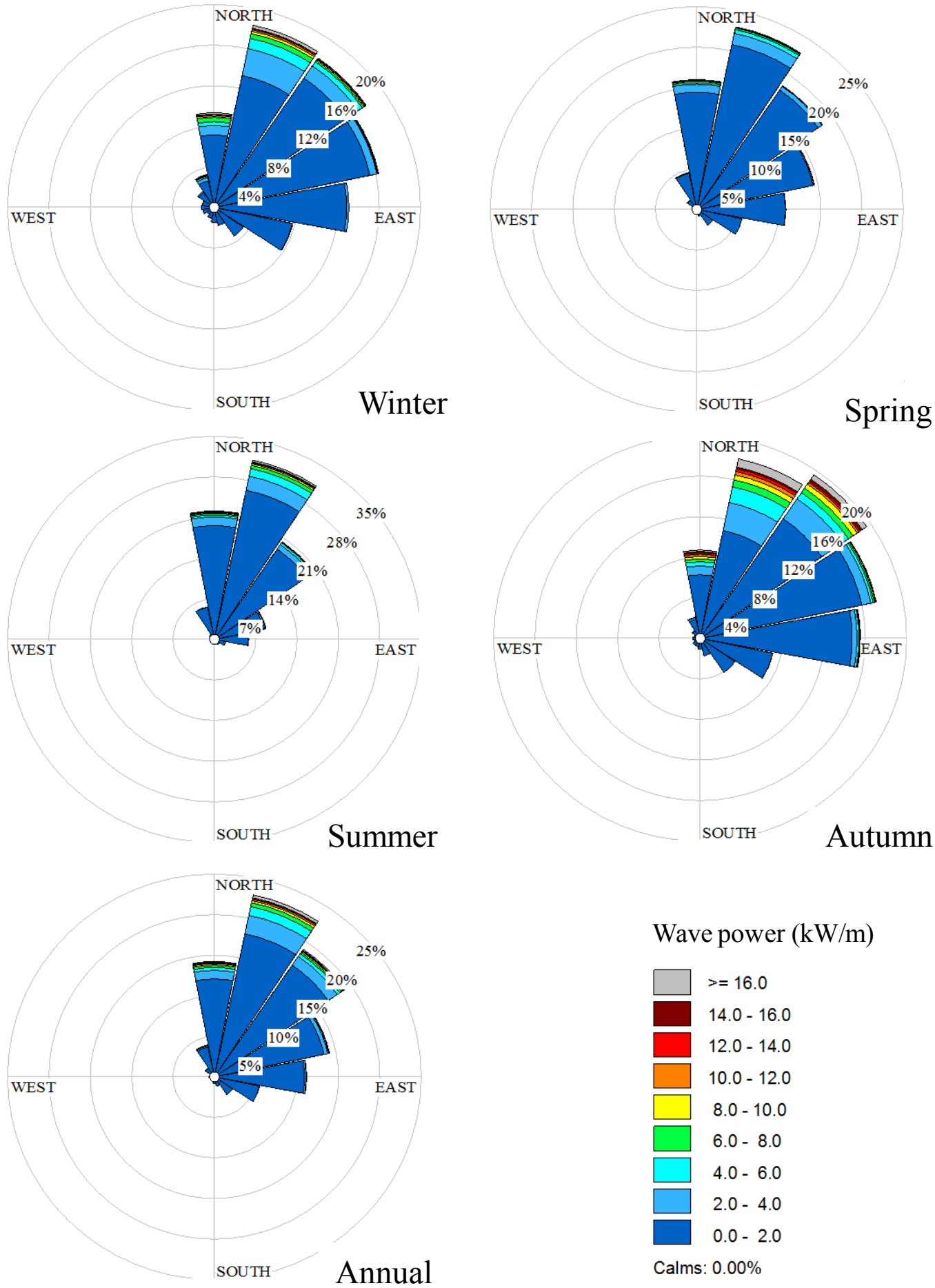

Wave power $(\mathrm{kW} / \mathrm{m})$

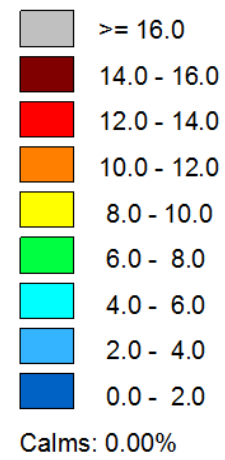

Fig. 9. Seasonal and annual wave power roses in Anzali 

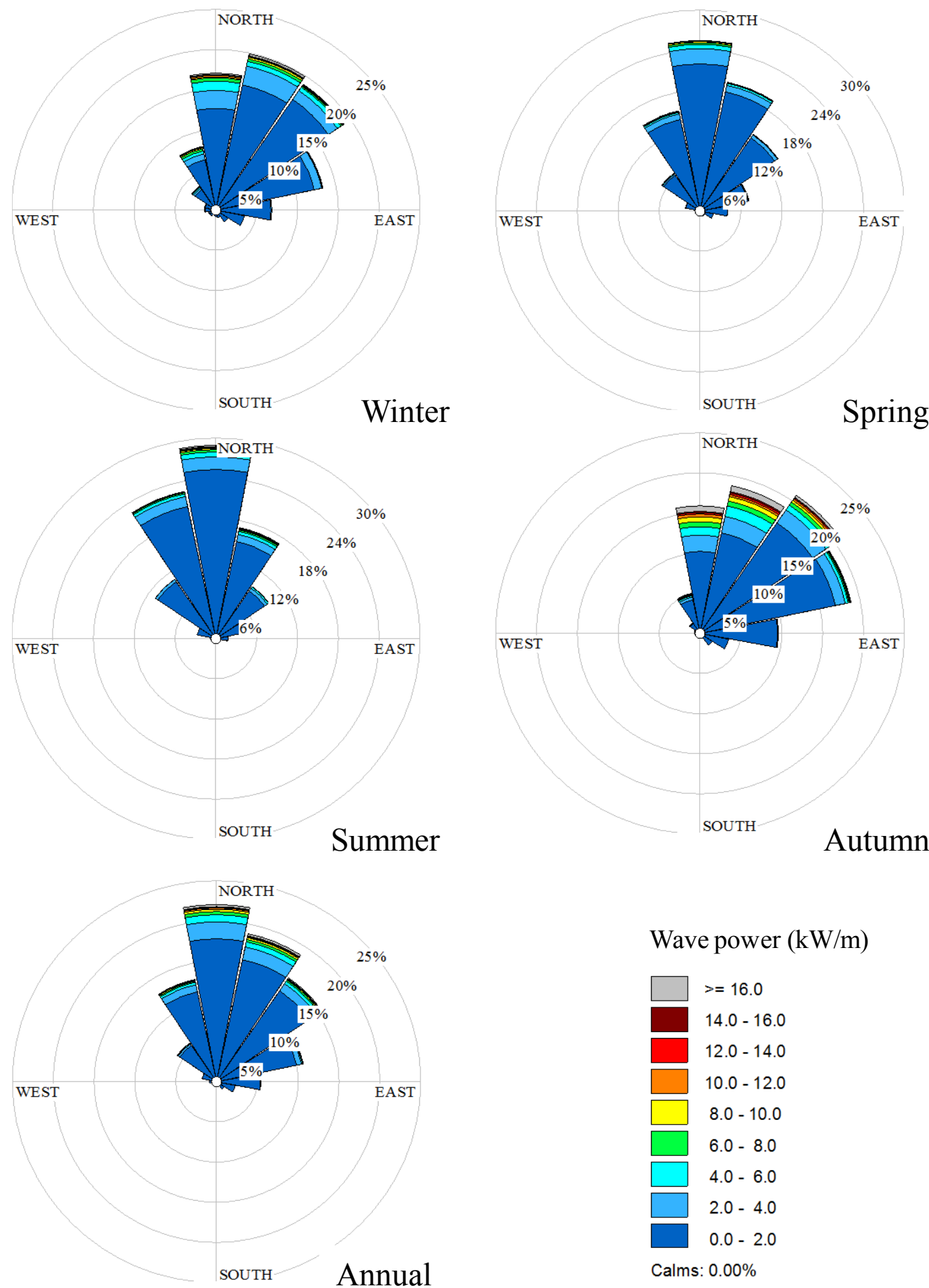

Wave power $(\mathrm{kW} / \mathrm{m})$

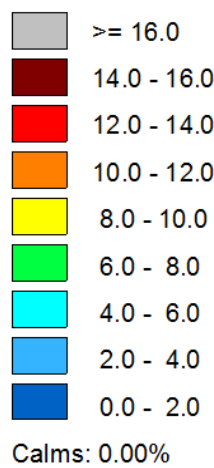

Fig. 10. Seasonal and annual wave power roses in Noshahr 

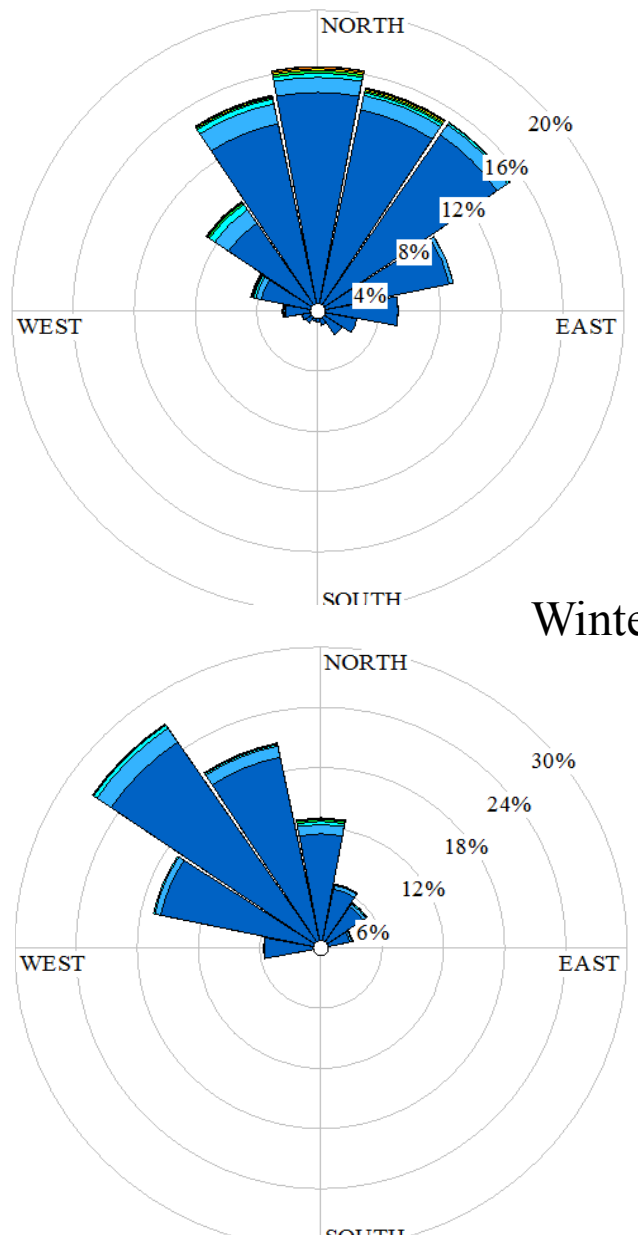

Summer

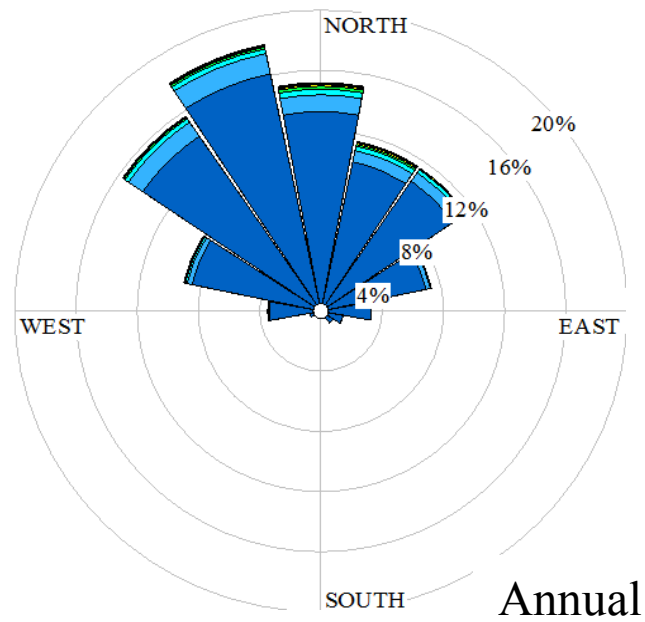

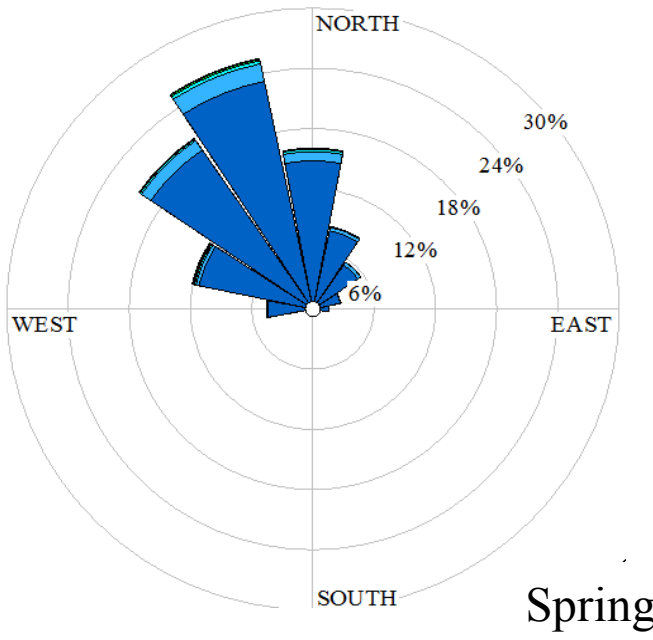

NORTH

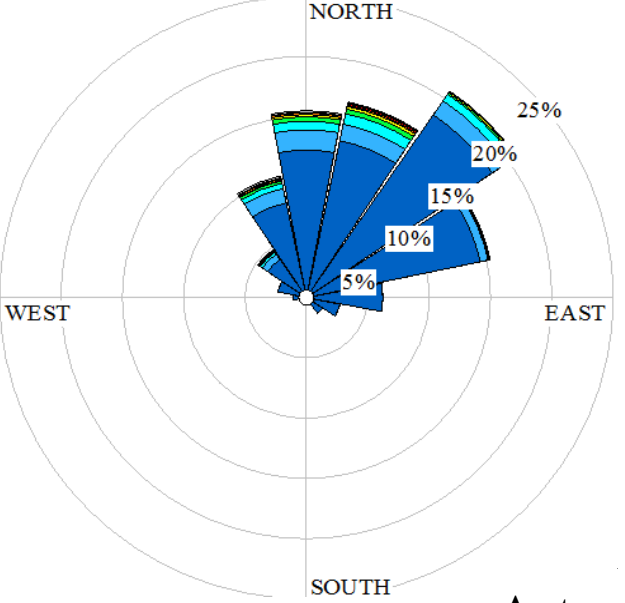

Autumn

Wave power $(\mathrm{kW} / \mathrm{m})$

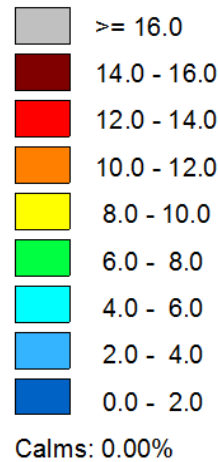

Fig. 11. Seasonal and annual wave power roses in Amirabad 


\subsubsection{Storage of wave energy}

To evaluate the possibility of utilizing the wave energy converters, the total and exploitable storages of wave energy were calculated using equations 9 and 10 .

$E_{t}=P_{\text {mean }} \times t$

$E_{e}=P_{\text {mean }} \times t_{e}$

where $E_{t}$ and $E_{e}$ are the total and exploitable storage of wave energy per unit area, respectively while $t$ and $t_{e}$ show the total hours all year round $(=8760 \mathrm{hr})$ and the exploitable time per unit area in theory, respectively. The $t_{e}$ is the hours with wave power values greater than $2 \mathrm{~kW} / \mathrm{m}$. This threshold was used to estimate $t_{e}$ because the wave energy worth exploitation when it is greater than $2 \mathrm{~kW} / \mathrm{m}$ (Zheng et al., 2013; Wen et al., 2013).

Table 4, represents the total and exploitable storage of wave energy in different stations. It can be found from this table that the highest total and exploitable wave energies exist in Noshahr where the total and exploitable storages of wave energy reach to $0.94 \times 10^{4}$ and $0.11 \times 10^{4} \mathrm{kWh} / \mathrm{m}$, respectively. Zhou et al. (2015) also obtained the total and exploitable storage of wave energy in the whole domain of Beibu Gulf and represented values of $1.2 \times 10^{4}$ and $0.26 \times 10^{4} \mathrm{kWh} / \mathrm{m}$ as the highest total and exploitable storages, respectively. However, the presented values in Beibu Gulf belong to central part of the domain, and they are smaller in nearshore areas (approximately $0.5 \times 10^{4}$ and $0.12 \times 10^{4} \mathrm{kWh} / \mathrm{m}$ for the total and exploitable storages, respectively).

Anzali, which is a major port, owns the second place with $0.81 \times 10^{4}$ and $0.08 \times 10^{4}$ $\mathrm{kWh} / \mathrm{m}$ as total and exploitable storages of wave energy, respectively. The lowest values of the total and exploitable storages of wave energy exist in Astara where these values are $0.51 \times 10^{4}$ and $0.03 \times 10^{4} \mathrm{kWh} / \mathrm{m}$, respectively; which shows the low 
frequency of high energy waves there. The obtained results show that even though the total wave energy in Noshahr is approximately 1.8 times greater than in that of Astara, the exploitable wave energy in Noshahr is approximately 3 times greater than that of Astara. This implies the frequency of higher-energy waves is more in Noshahr, compared to Astara, Anzali and Amirabad. Therefore, Noshahr, which is located in the central part of the southern Caspian Sea, is suggested as the best location for wave energy harvesting.

Table 4. Mean wave power, exploitable time and total and exploitable storages of wave energy

\begin{tabular}{lllll}
\hline Station: & Astara & Anzali & Noshahr & Amirabad \\
\hline$P_{\text {mean }}(\mathrm{kW} / \mathrm{m})$ & 0.59 & 0.93 & 1.07 & 0.75 \\
$t_{e}(\mathrm{hr})$ & 632.45 & 931.09 & 1087.09 & 775.91 \\
$E_{t}(\mathrm{kWh} / \mathrm{m})$ & 5149.14 & 8107.12 & 9360.95 & 6596.10 \\
$E_{e}(\mathrm{kWh} / \mathrm{m})$ & 371.76 & 861.70 & 1161.67 & 584.24 \\
\hline
\end{tabular}

\subsubsection{Inter-annual variations in wave power}

To evaluate the stability of available wave power in an area, assessment of the interannual variations is also required to consider annual variations. As mentioned before, the assessment of inter-annual variability of the wave power is critical for determining the feasibility of utilizing the wave energy converter technology (Neill and Hashemi, 2013). In addition, Kamranzad et al. (2013) assessed the inter-annual variation of the wave energy for about three decades and showed that there is a significant decrease in a ten-yearly period due to a smooth decrease of wind speeds.

Using 11 years of available data, the inter-annual wave power variations were obtained and plotted in Fig. 12. This figure depicts a relatively stable annual wave 
condition, except for the years 1992 to 1995, when an increase in wave power occurred in 1993 and then, the wave power decreased in all stations. In addition, the increase of the wave power in 1993 is higher in Noshahr compared to that of the other stations. The inter-annual variation of the mean annual wave power shows that in most of the years, the wave power was the highest in Noshahr. Therefore, it can be concluded that there is a relatively stable condition for wave energy resources during the period of available data.

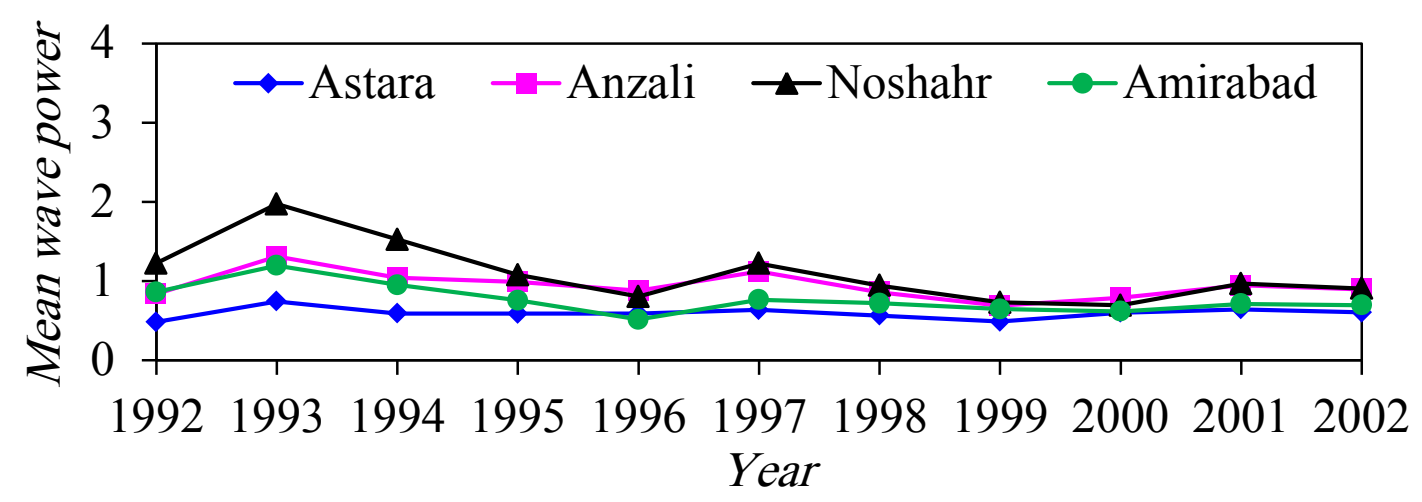

Fig. 12. Inter-annual distributions of mean wave power $(\mathrm{kW} / \mathrm{m})$ in different stations

\section{Conclusions}

In this study, eleven years of simulated wave characteristics were used to estimate the wave power potential in the southern Caspian Sea. Annual and seasonal distributions of the wave power in the domain showed that the richest area is located in the central part of the southern Caspian Sea and then in the western parts with a maximum of 1.5 $\mathrm{kW} / \mathrm{m}$ for the mean wave power.

The seasonal distributions of the mean wave power showed that the highest wave power $(2.2 \mathrm{~kW} / \mathrm{m})$ exists in autumn and reaches the lowest value $(0.95 \mathrm{~kW} / \mathrm{m})$ in spring. In all seasons, the highest and lowest wave powers exist in the central and eastern parts of the southern Caspian Sea, respectively. Monthly variation of the wave 
power also indicated the highest wave power values correspond to November while the lowest values exist during April to August. In addition, almost in all months, the mean wave power is higher in the central areas of the southern Caspian Sea while the western parts become energetic as well in October and November.

The wave power was also evaluated in four nearshore stations named Astara, Anzali, Noshahr and Amirabad located in the north-western, western, central and eastern parts of the domain and the seasonal variations of the mean and maximum wave power were assessed there. The results showed that in all stations, the highest and lowest mean wave powers exist in autumn and spring, respectively and the mean wave powers are the highest and lowest in Noshahr and Astara, respectively. Furthermore, the maximum wave power is higher in Noshahr except during spring when the maximum wave power in Amirabad is slightly higher.

The mean, maximum and $10 \%$ exceedance of the wave power are higher during September to November and reach the highest values in November. The wave power is the lowest during March to August, almost in all stations; and the available mean and extreme wave powers are the lowest in Astara. However, the mean and maximum wave power in Amirabad exceeds those of other stations during April to June and March to April, respectively. Seasonal and monthly variability indices showed that the wave power variation is lower in Amirabad compared to other stations. However, the amount of the variability indices in other stations implies a relatively stable wave condition, and the seasonality of all stations is rather low.

Directional distribution of the wave power was also investigated, and the results showed that the wave propagation direction is relatively stable in Astara while it is substantial in Amirabad. In addition, the dominant wave direction is from NE during autumn in all stations. The total and exploitable wave energies were also calculated 
and the results indicated that the highest values exist in Noshahr, as expected; where the total and exploitable storages of wave energy are $0.94 \times 10^{4}$ and $0.11 \times 10^{4} \mathrm{kWh} / \mathrm{m}$, respectively, which are comparable with the available values in other areas. Then, Anzali has the richest wave energy, while the lowest values belong to Astara. Inter-annual variations of the mean wave power showed a relatively stable condition for wave energy resources during the period of available data. Therefore, the low seasonal and inter-annual variations and the amount of exploitable storages of wave energy, make the southern Caspian Sea a suitable area for providing a part of energy demand from the wave energy.

Between the four stations, Astara has the most stable wave directional variation, but considering its low wave power and also low total and exploitable wave energy values; it is not an appropriate location for wave energy harvesting. On the contrary, Noshahr with high mean wave power and also higher total and exploitable wave energy values, is suggested as the most appropriate location for wave energy extraction in the southern coasts of the Caspian Sea. In addition, taking the second place out of four selected stations, Anzali seems more appropriate for wave energy harvesting due to its higher wave power and exploitable wave energy, especially during autumn.

This study showed that the mean wave power is rather low in the southern Caspian Sea comparing to the global estimations. However, taking in to account the low seasonality and negligible inter-annual variations of the available wave energy resources, as well as having comparable total and exploitable storages of wave energy, makes this enclosed water body a potential place for developers and decision makers to provide a part of the energy demand of adjacent areas. 


\section{Acknowledgement}

The authors are thankful to SWAN groups at Delft University of Technology for making the model freely available. 


\section{References}

Abbaspour M, Rahimi R. Iran atlas of offshore renewable energies. Renew Energy 2011;36:388-98.

Amirahmadi H. The Caspian Region at a Crossroad: Challenges of a New Frontier of Energy and Development. Palgrave Macmillan; 2000, p. 112. ISBN 978-0-31222351-9.

Appendini CM, Urbano-Latorre CP, Figueroa B, Dagua-Paz CJ, Torres-Freyermuth A, Salles P. Wave energy potential assessment in the Caribbean Low Level Jet using wave hindcast information. Appl Energy 2015;137:375-84.

Booij N, Ris RC, Holthuijsen LH. A third-generation wave model for coastal regions. 1. Model Description and validation. J Geophys Res 1999;104:7649-66.

Chegini V, Golshani AA, Taebi S. Iranian Seas Wave Modeling project. Iranian National Institute for Oceanography and Atmospheric Science; 2006 (in Persian). Cornett AM. A global wave energy resource assessment. International offshore and polar engineering conference, Vancouver, Canada 2008;318-26.

Etemad-Shahidi A, Kamranzad B, Chegini V. Wave energy estimation in the Persian Gulf. Proc Intl Conference on Environmental Pollut Remediation, Canada 2011;223. Hadadpour S, Etemad-Shahidi A, Jabbari E, Kamranzad B. Wave Energy and hot spots in Anzali port. Energy 2014z;74:529-36.

Haddadpour S, Etemad-Shahidi A, Kamranzad B. Wave energy forecasting using artificial neural networks in the Caspian Sea. Proc Ins Civil Eng-Mar En $2014 b ; 167: 42-52$.

Haddadpour S, Etemad-Shahidi A, Kamranzad B. Wave power investigation along the coastline of the Anzali. Proc $11^{\text {th }}$ Intl Conference Coasts, Ports and Marine Structures 2014c;662-6. 
Henfridsson U, Neimane V, Strand K, Kapper R, Bernhoff H, Danielsson O, et al. Wave energy potential in the Baltic Sea and the Danish part of the North Sea, with reflections on the Skagerrak. Renew Energy 2007;32:2069-84.

Hiles CE, Buckham BJ, Wild P, Robertson B. Wave energy resources near Hot Spring Cove, Canada. Renew Energy 2014;71:598-608.

Hughes MG, Heap AD. National-scale wave energy resource assessment for Australia. Renew Energy 2010;35:1783-91.

Kamranzad B, Etemad-Shahidi A, Chegini V. Assessment of wave energy variation in the Persian Gulf. Ocean Eng 2013;70:72-80.

Kamranzad B, Etemad-Shahidi A, Chegini V. Wave energy assessment in the Caspian Sea. Proc $18^{\text {th }}$ congress of the IAHR-APD, Jeju, South Korea 2012;424-5.

Kamranzad B, Etemad-Shahidi A, Chegini V, Yeganeh-Bakhtiyari A. Climate

Change impact on wave energy in the Persian Gulf. Ocean Dynamics 2015;65:77794.

Leijon M, Bernhoff H, Berg M, Ågren O. Economical considerations of renewable electric energy production-especially development of wave energy. Renew Energy 2003;8:1201-9.

López M, Veigas M, Iglesias G. On the wave energy resource of Peru. Energy Convers Management. 2015;90:34-40.

Mirzaei A, Tangang F, Juneng L. Wave energy potential assessment in the central and southern regions of the South China Sea. Renew Energy 2015;80:454-70.

Moeini MH, Etemad-Shahidi A, Chegini V, Rahmani I. Wave data assimilation using a hybrid approach in the Persian Gulf. Ocean Dynamics 2012;62:785-97.

Monteforte M, Lo Re C, Ferreri GB. Wave energy assessment in Sicily (Italy). Renew Energy 2015;78:276-87. 
Morim J, Cartwright N, Etemad-Shahidi A, Strauss D, Hemmer M. A review of wave energy estimates for nearshore shelf waters off Australia, International J Marine Energy 2014;7:57-70.

Neill SP, Hashemi MR. Wave power variability over the northwest European shelf seas. Appl Energy 2013;106:31-46.

Neill SP, Lewis MJ, Hashemi MR, Slater E, Lawrence J, Spall SA. Inter-annual and inter-seasonal variability of the Orkney wave power resource. Appl energy 2014;132: $339-48$.

Ortega S, Osorio AF, Agudelo P. Estimation of the wave power resource in the Caribbean Sea in areas with scarce instrumentation. Case study: Isla Fuerte, Colombia. Renew Energy 2013;57:240-8.

Panicker NN. Power resource potential of ocean surface wave. In: The Wave and Salinity Gradient Workshop, Newark, Delaware, USA, 1976;1-48.

Portilla J, Sosa J, Cavaleri L. Wave energy resources: Wave climate and exploitation. Renew Energy 2013;57:594-605.

Rusu E, Onea F. Evaluation of the wind and wave energy along the Caspian Sea. Energy 2013;50:1-14.

Reguero BG, Losada IJ, Méndez FJ. A global wave power resource and its seasonal, interannual and long-term variability. Appl Energy 2015;148:366-80.

Rute Bento A, Martinho P, Guedes Soares C. Numerical modeling of the wave energy in Galway Bay. Renew Energy 2015;78:457-66.

Sanil Kumar V, Anoop TR. wave energy resource assessment for the Indian shelf seas. Renew Energy 2015;76:212-9.

Wen B, Xue YG, Zhang FR, Zhao CY. Numerical simulation of wave energy resources in the China Sea. Mar forecasts 2013;30:36-41. 
Wu S, Liu C, Chen X. Offshore wave energy resource assessment in the East China Sea. Renew Energy 2015;76:628-36.

Zheng CW, Li CY. Variation of the wave energy and significant wave height in the China Sea and adjacent waters. Renew sustainable energy reviews 2015;43:381-7. Zheng CW, Pan J, Li JX. Assessing the China Sea wind energy and wave energy resources from 1988 to 2009. Ocean Eng 2013;65:39-48.

Zhou G, Huang J, Yue T, Luo Q, Zhang G. Temporal-Spatial distribution of wave energy: A case study of Beibu Gulf, China. Renew Energy 2015;74:344-56. 


\section{Figure Captions}

Fig. 1. Location of the Caspian Sea, computational domain and nearshore stations

Fig. 2. Location, bathymetry and depth contours of the southern Caspian Sea

Fig. 3. Annual wave power distribution in southern Caspian Sea

Fig. 4. Seasonal mean wave power distribution in southern Caspian Sea

Fig. 5. Monthly mean wave power distribution in southern Caspian Sea

Fig. 6. Seasonal wave power $(\mathrm{kW} / \mathrm{m})$ in different stations

Fig. 7. Monthly wave power $(\mathrm{kW} / \mathrm{m})$ in different stations

Fig. 8. Seasonal and annual wave power roses in Astara

Fig. 9. Seasonal and annual wave power roses in Anzali

Fig. 10. Seasonal and annual wave power roses in Noshahr

Fig. 11. Seasonal and annual wave power roses in Amirabad

Fig. 12. Inter-annual distributions of mean wave power $(\mathrm{kW} / \mathrm{m})$ in different stations 
Black and white figures (Black and white in print is required)

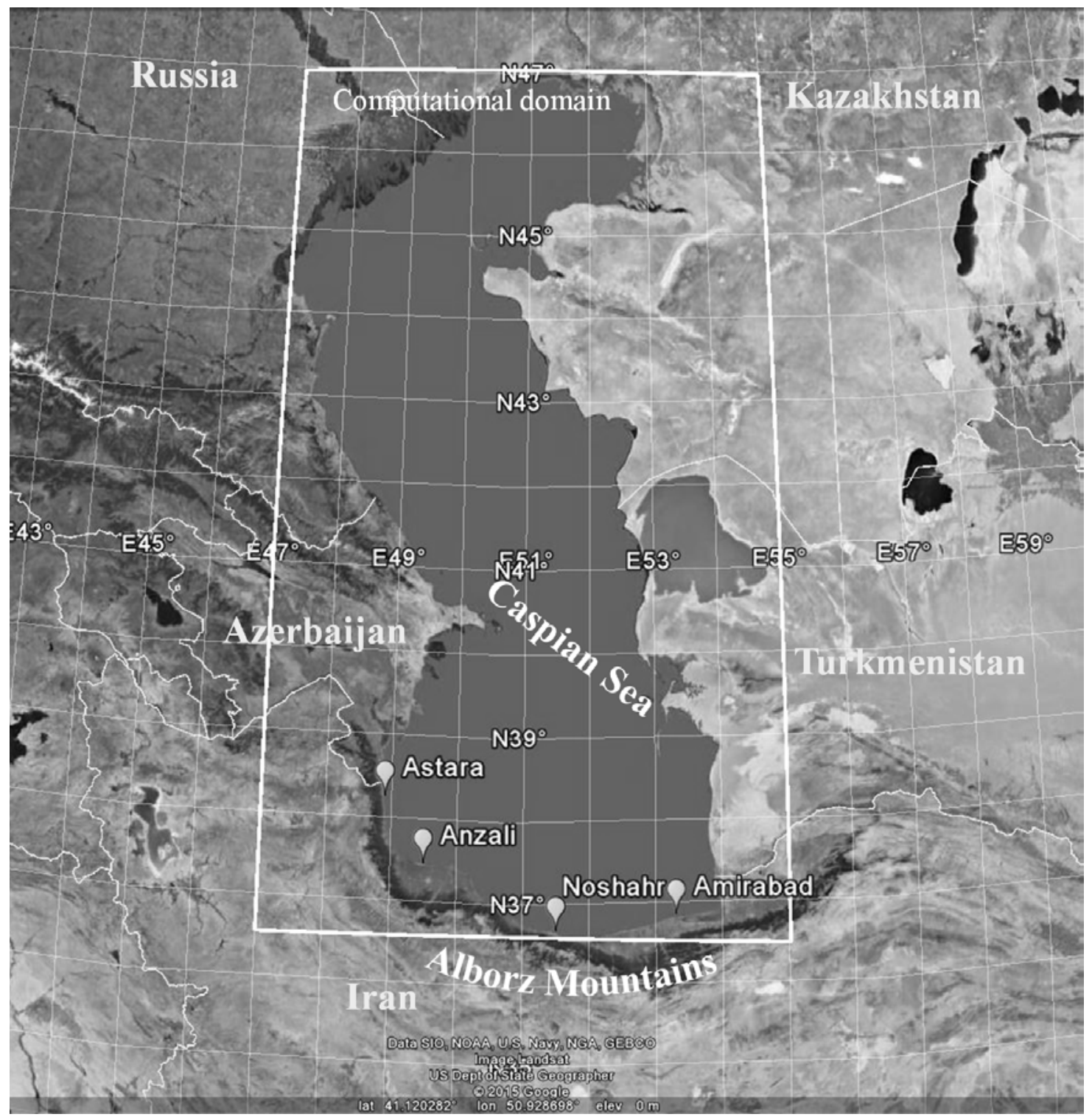

Fig. 1. Location of the Caspian Sea, computational domain and nearshore stations 


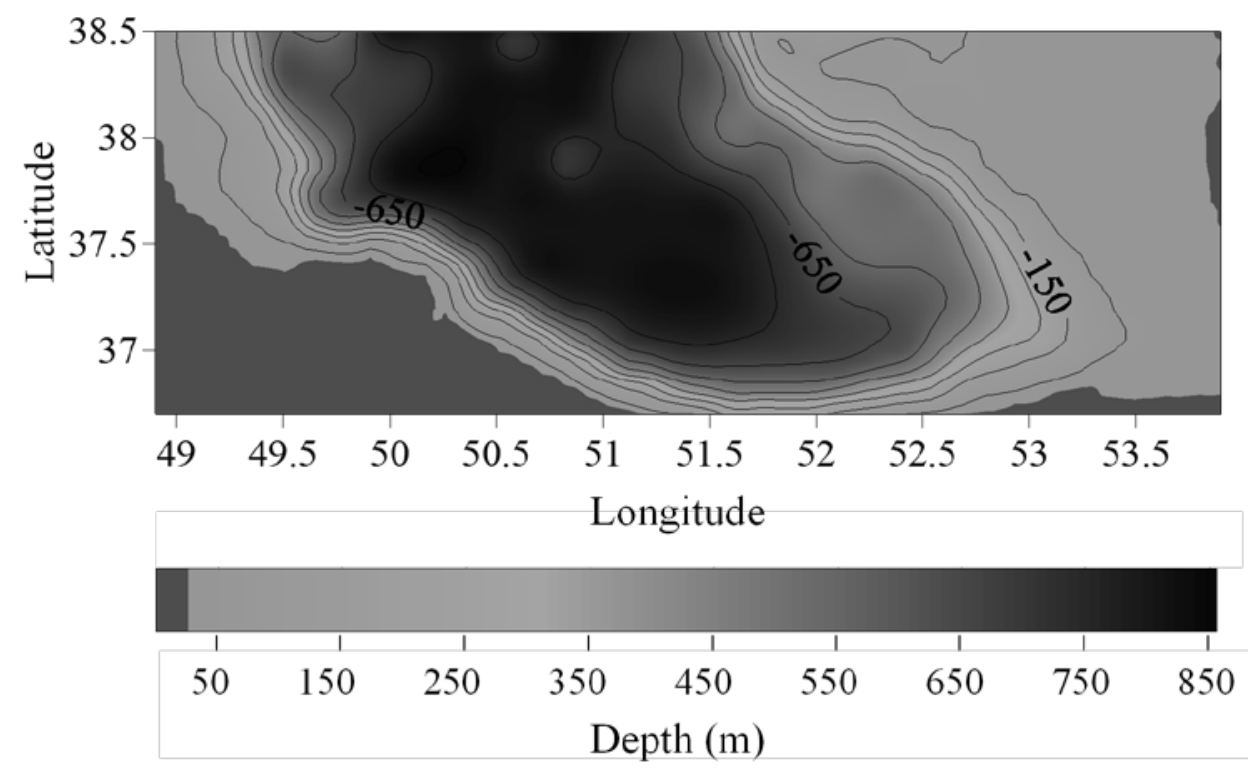

Fig. 2. Location, bathymetry and depth contours of the southern Caspian Sea 


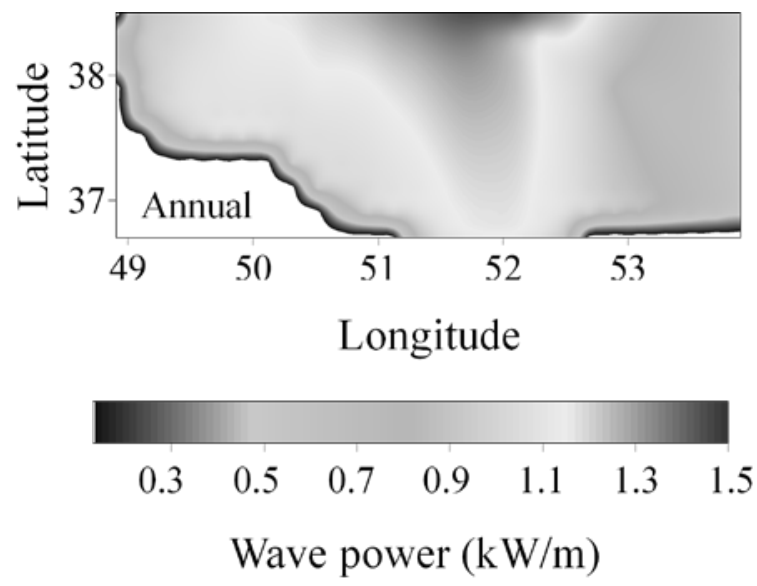

Fig. 3. Annual wave power distribution in southern Caspian Sea 

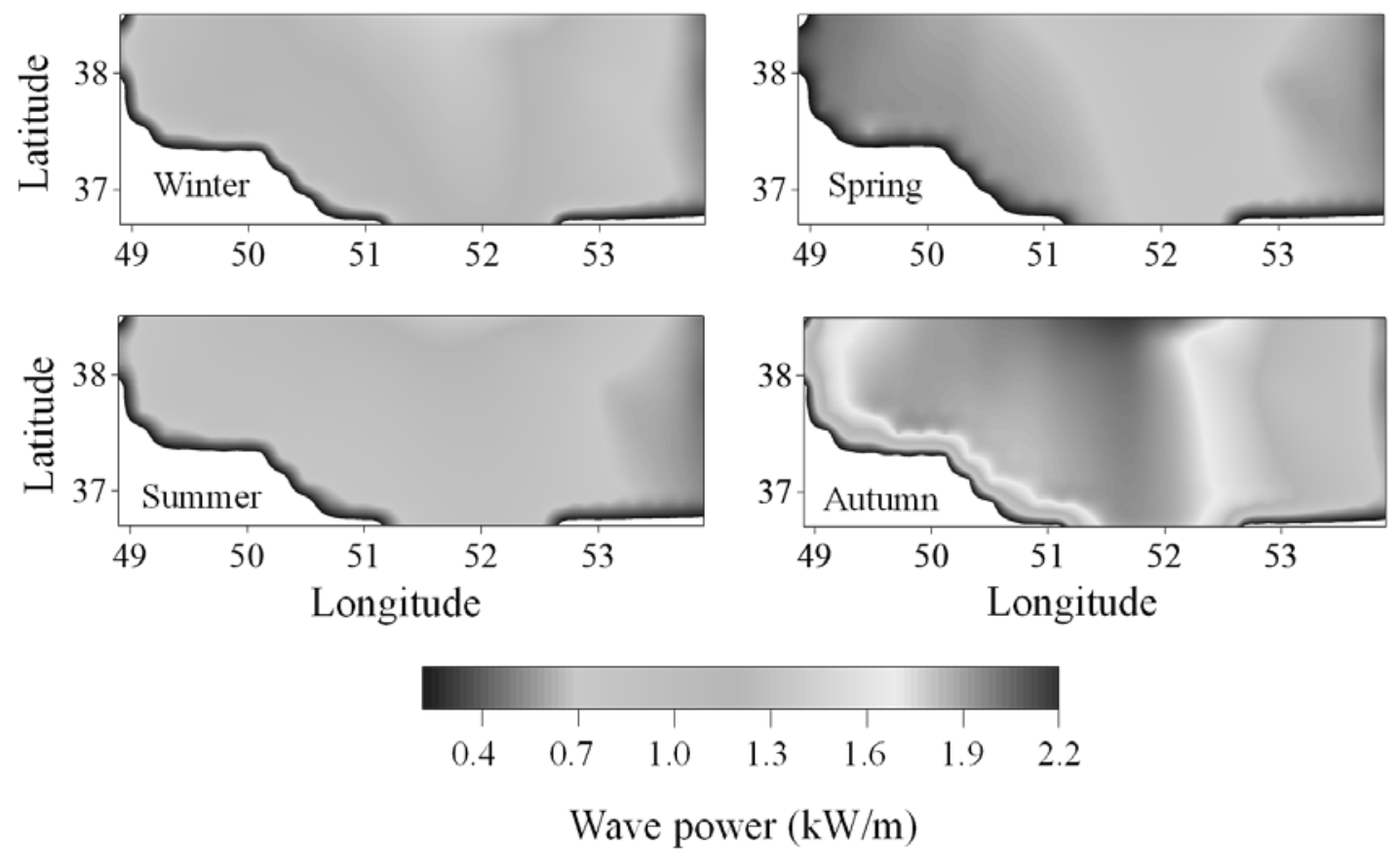

Fig. 4. Seasonal mean wave power distribution in southern Caspian Sea 

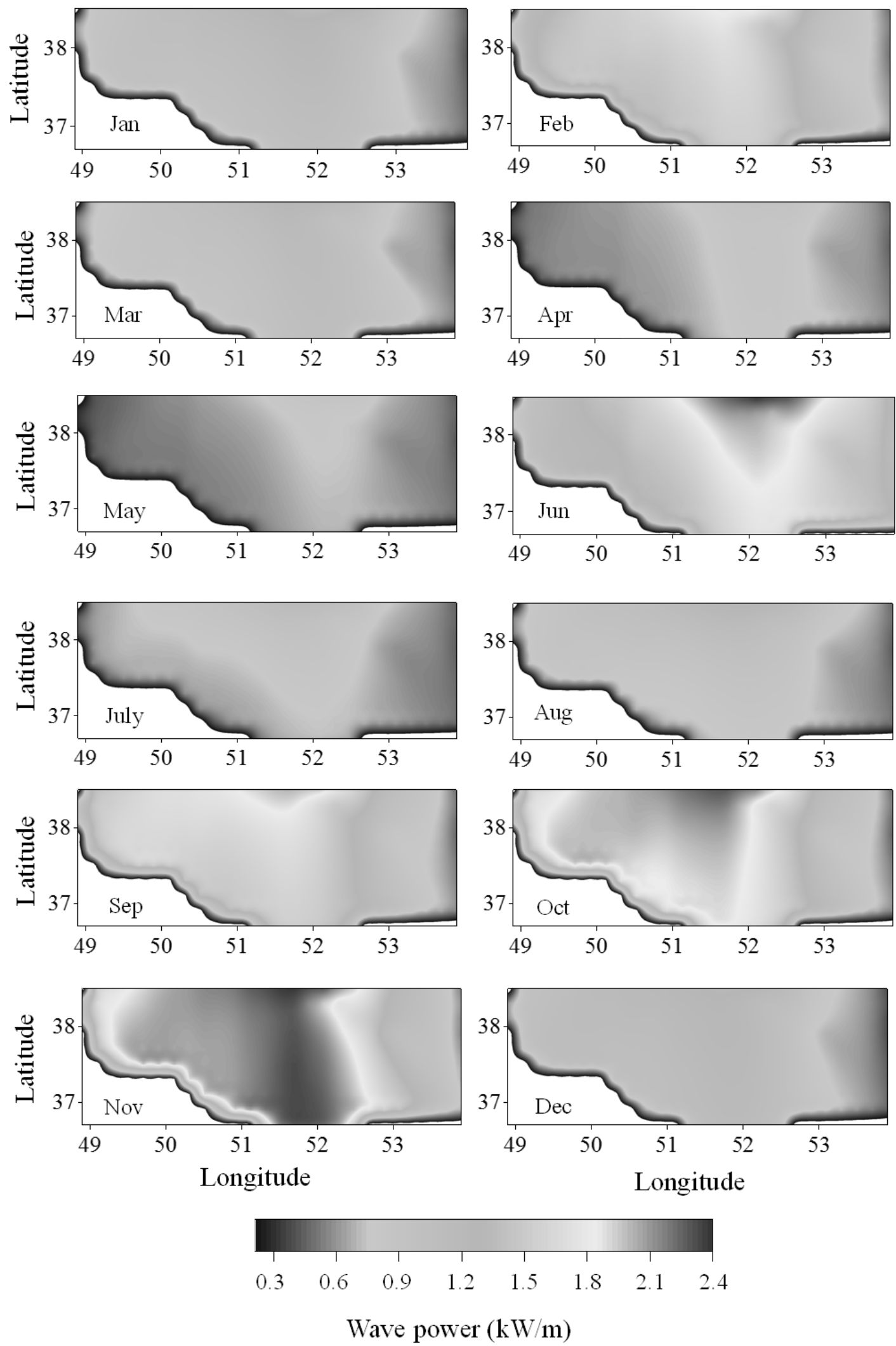

Fig. 5. Monthly mean wave power distribution in southern Caspian Sea 

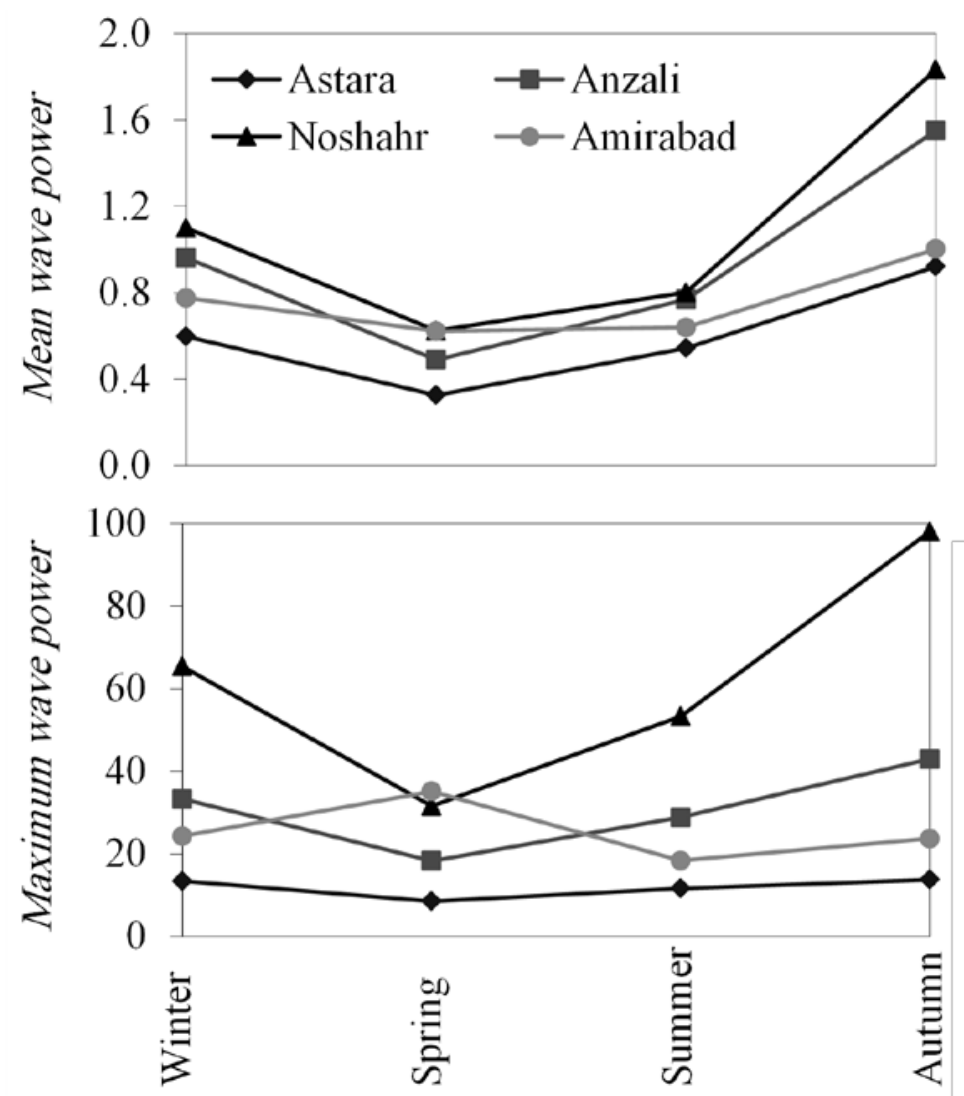

Fig. 6. Seasonal wave power $(\mathrm{kW} / \mathrm{m})$ in different stations 

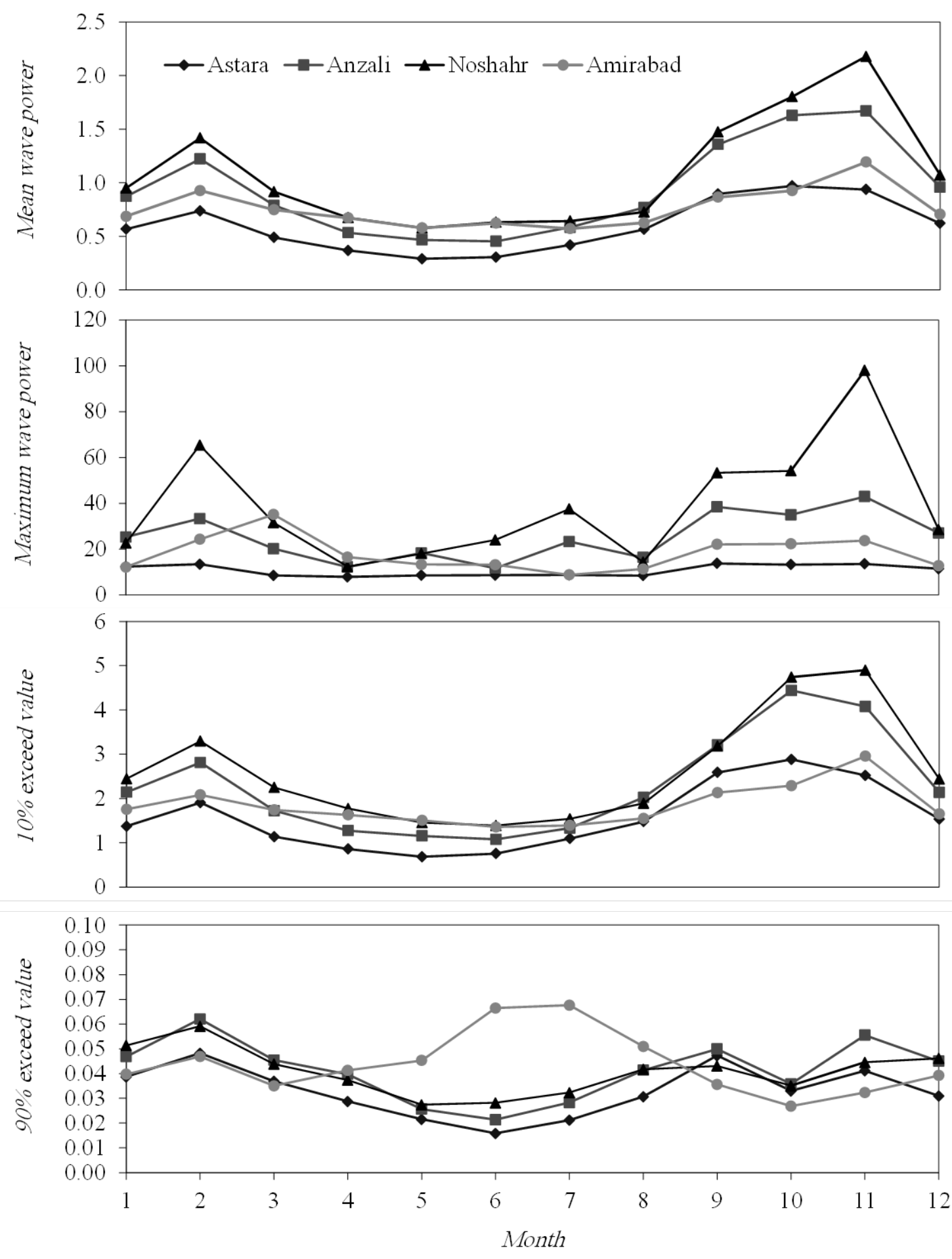

Fig. 7. Monthly wave power $(\mathrm{kW} / \mathrm{m})$ in different stations 

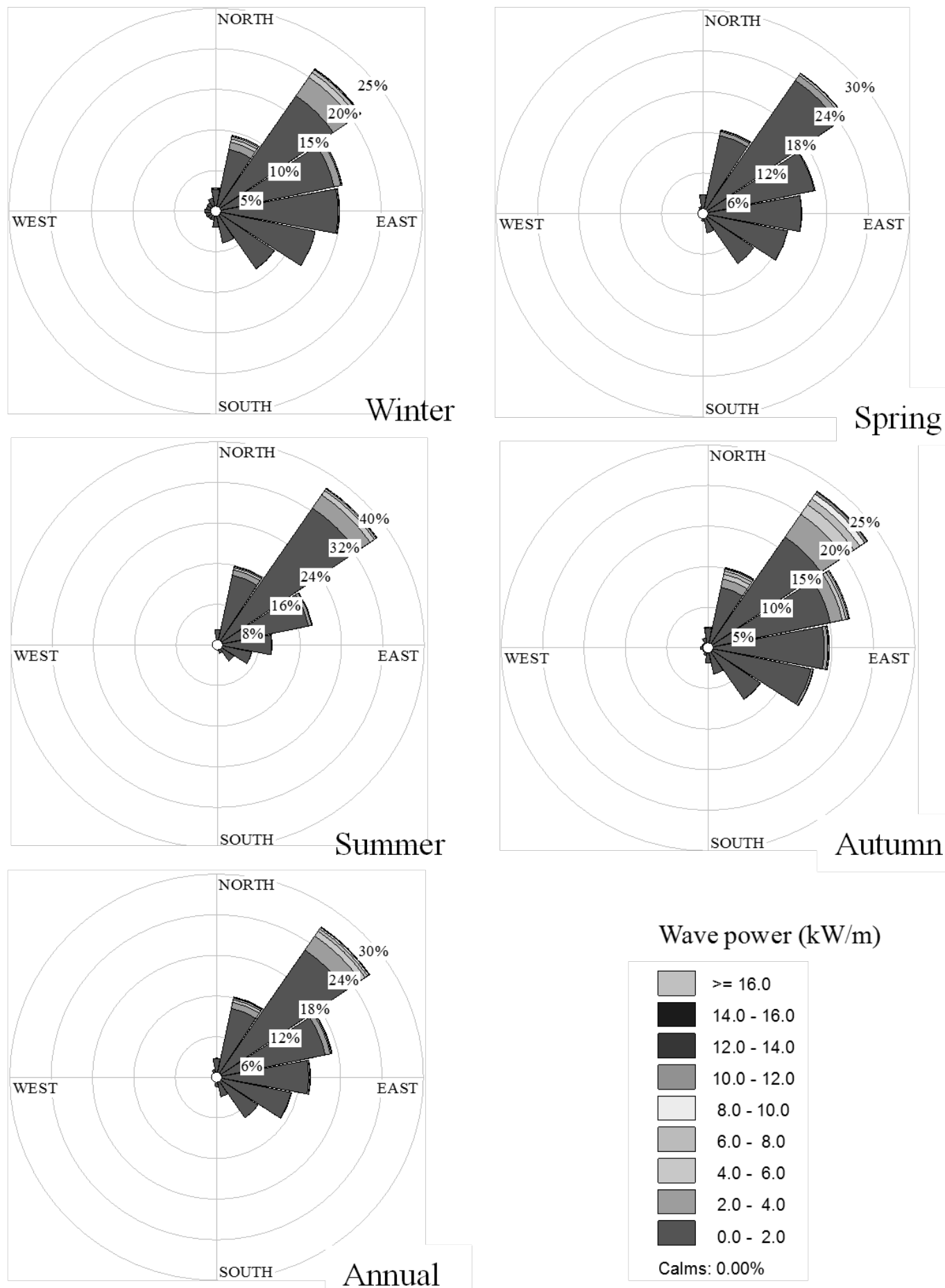

Wave power $(\mathrm{kW} / \mathrm{m})$

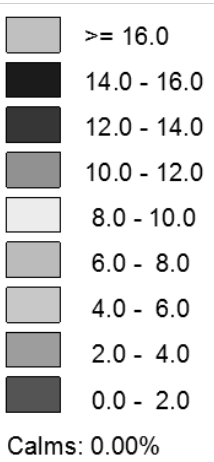

Fig. 8. Seasonal and annual wave power roses in Astara 

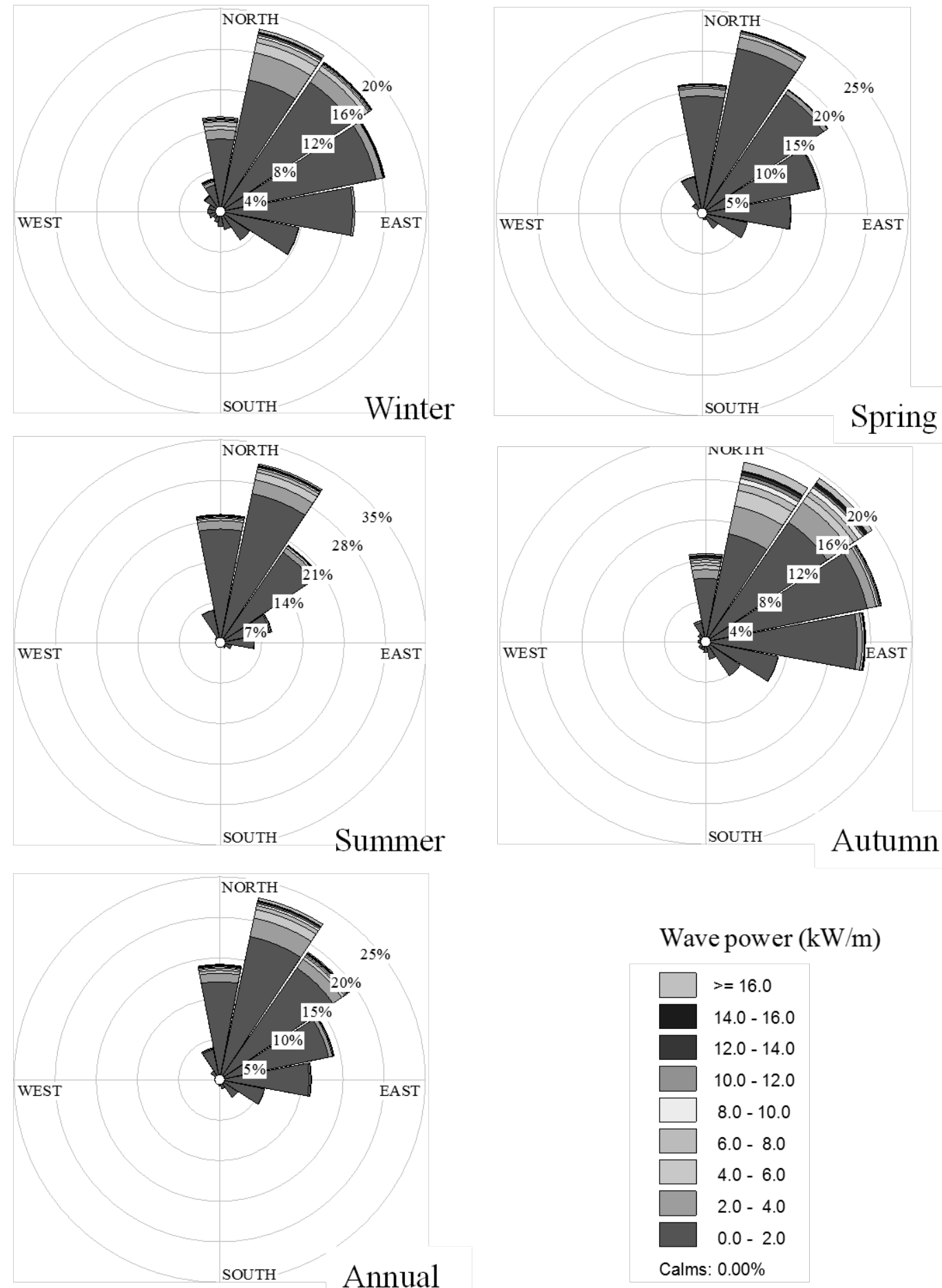

Wave power $(\mathrm{kW} / \mathrm{m})$

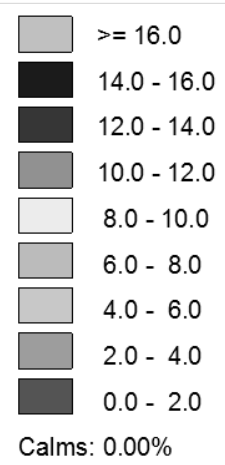

Fig. 9. Seasonal and annual wave power roses in Anzali 

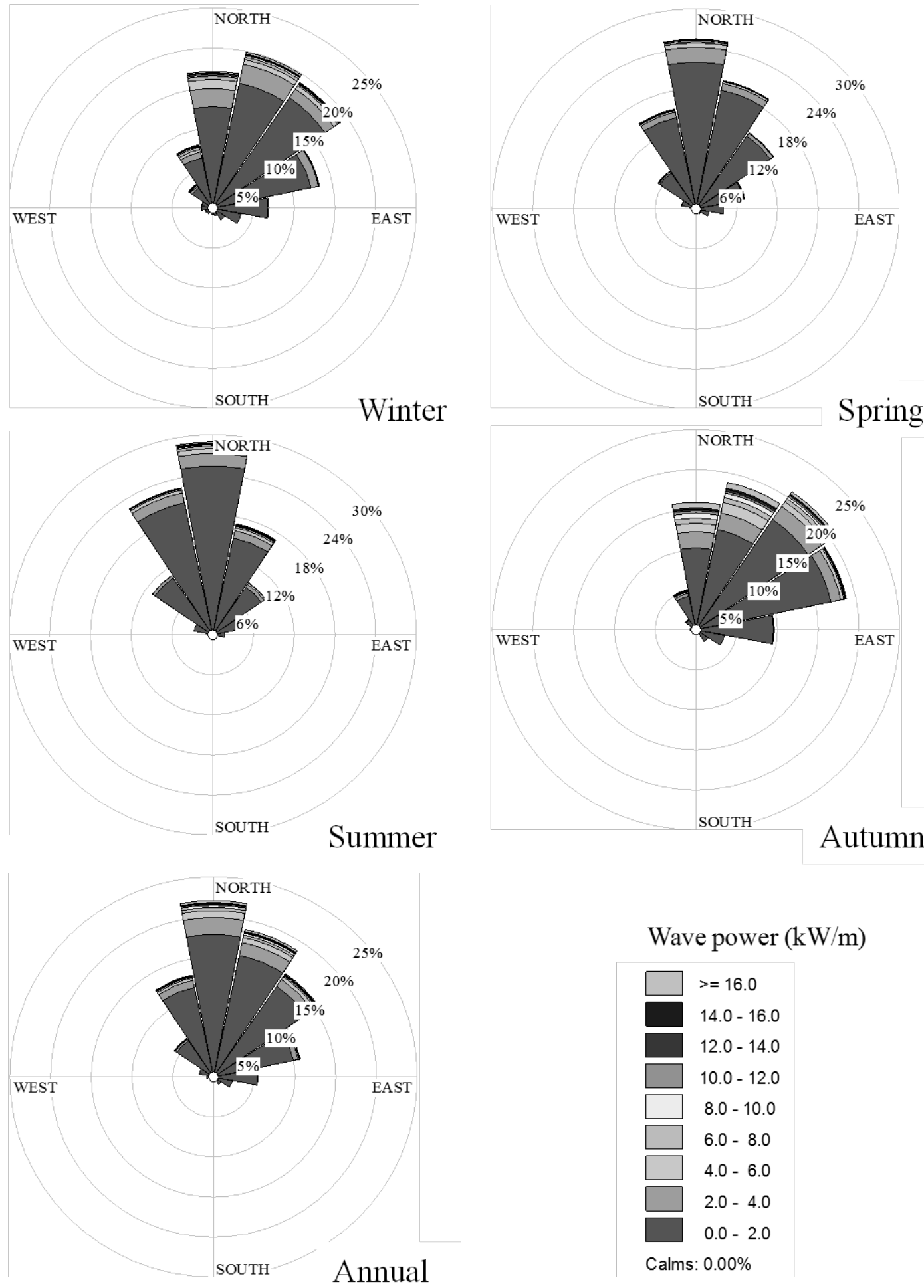

Wave power $(\mathrm{kW} / \mathrm{m})$

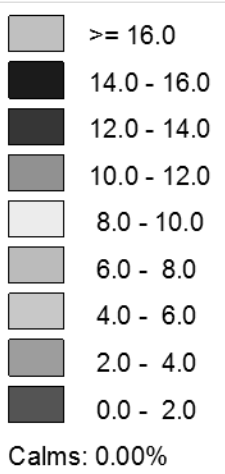

Fig. 10. Seasonal and annual wave power roses in Noshahr 

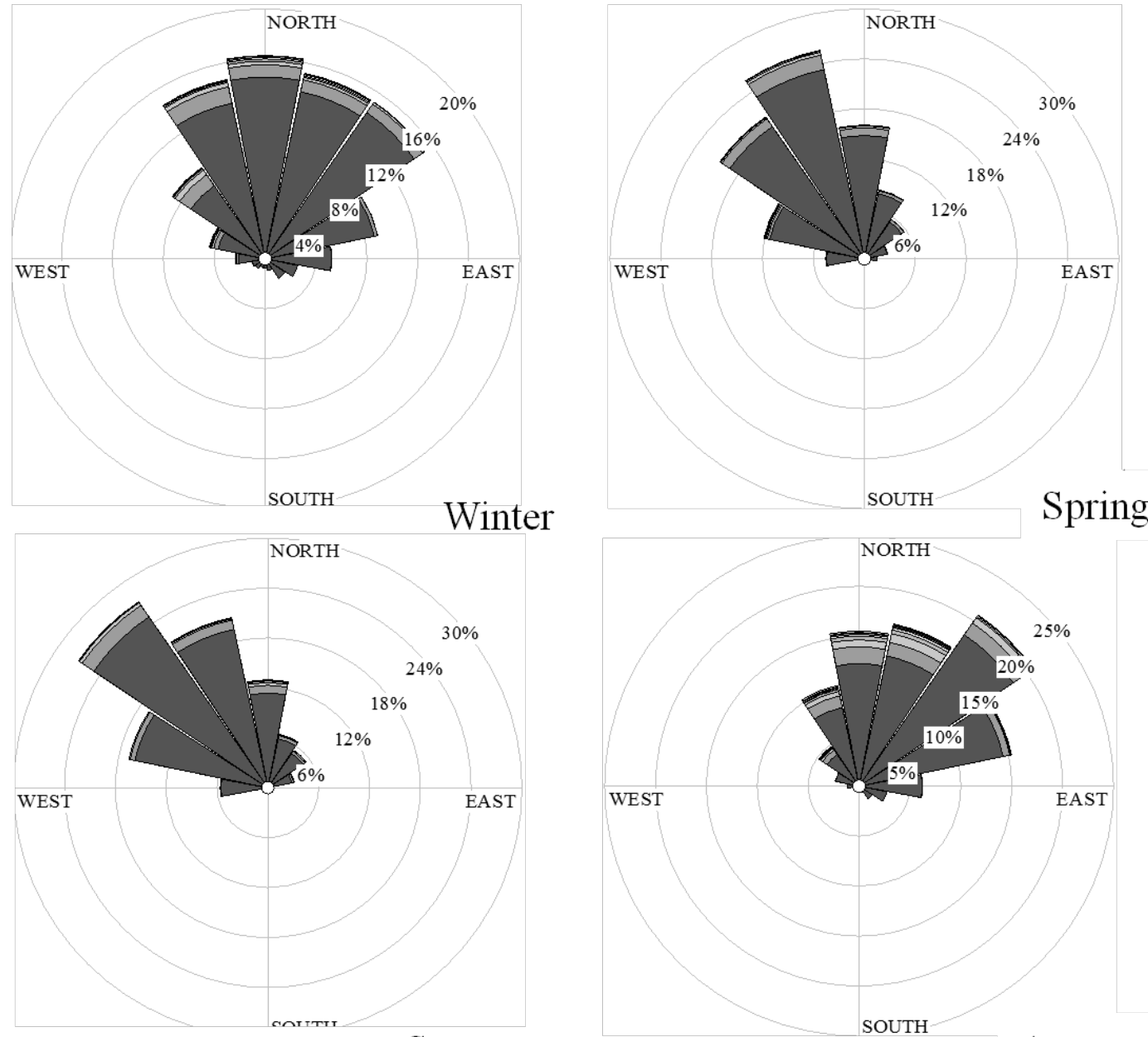

Summer
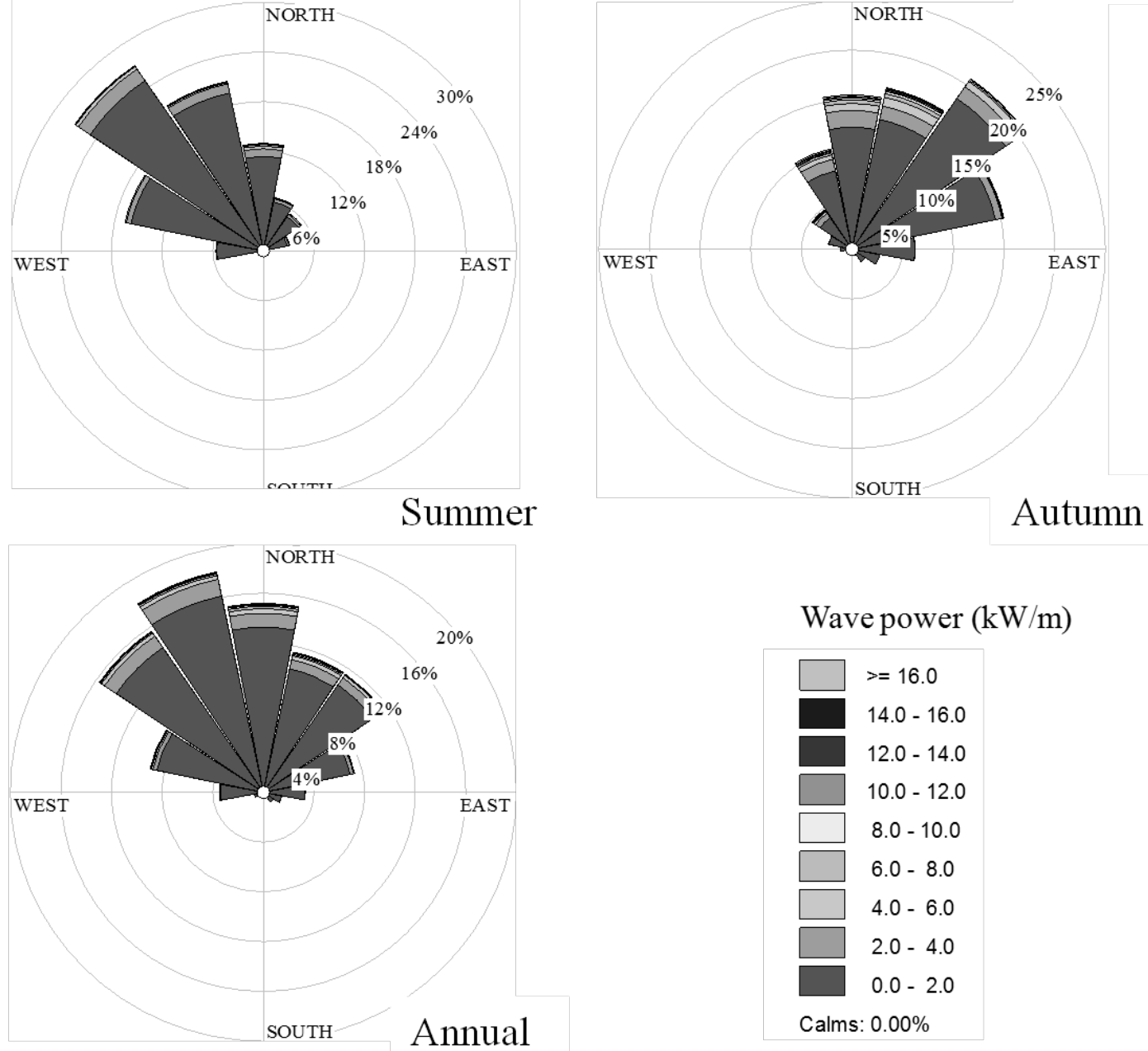

Wave power $(\mathrm{kW} / \mathrm{m})$

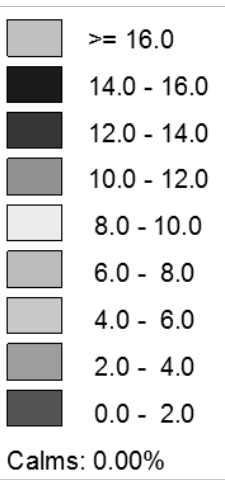

Fig. 11. Seasonal and annual wave power roses in Amirabad 


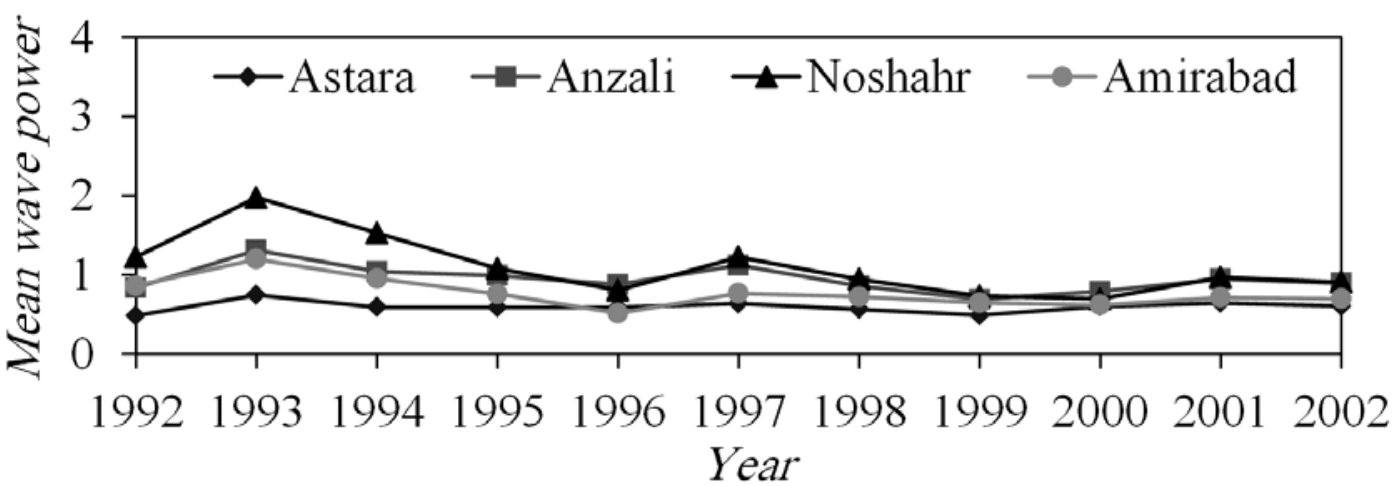

Fig. 12. Inter-annual distributions of mean wave power $(\mathrm{kW} / \mathrm{m})$ in different stations 